\section{What theories underpin performance-based financing? A scoping review}

\author{
Elisabeth Paul \\ School of Public Health, Universite Libre de Bruxelles, Brussels, Belgium \\ Oriane Bodson \\ Universite de Liege, Liege, Belgium, and \\ Valéry Ridde \\ CEPED, Institute for Research on Sustainable Development (IRD), \\ IRD-Université de Paris, Paris, France
}
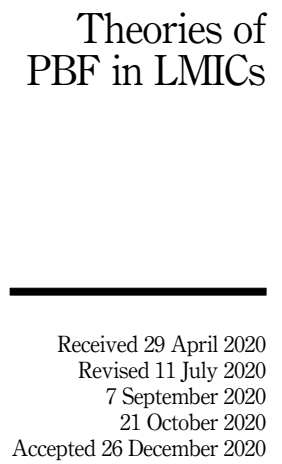

\begin{abstract}
Purpose - The study aims to explore the theoretical bases justifying the use of performance-based financing $(\mathrm{PBF})$ in the health sector in low- and middle-income countries (LMICs).

Design/methodology/approach - The authors conducted a scoping review of the literature on PBF so as to identify the theories utilized to underpin it and analyzed its theoretical justifications.

Findings - Sixty-four studies met the inclusion criteria. Economic theories were predominant, with the principal-agent theory being the most commonly-used theory, explicitly referred to by two-thirds of included studies. Psychological theories were also common, with a wide array of motivation theories. Other disciplines in the form of management or organizational science, political and social science and systems approaches also contributed. However, some of the theories referred to contradicted each other. Many of the studies included only casually alluded to one or more theories, and very few used these theories to justify or support PBF. No theory emerged as a dominant, consistent and credible justification of PBF, perhaps except for the principalagent theory, which was often inappropriately applied in the included studies, and when it included additional assumptions reflecting the contexts of the health sector in LMICs, might actually warn against adopting PBF. Practical implications - Overall, this review has not been able to identify a comprehensive, credible, consistent, theoretical justification for using $\mathrm{PBF}$ rather than alternative approaches to health system reforms and healthcare providers' motivation in LMICs.
\end{abstract}

Originality/value - The theoretical justifications of PBF in the health sector in LMICs are under-documented. This review is the first of this kind and should encourage further debate and theoretical exploration of the justifications of PBF.

Keywords Performance-based financing, Low- and middle-income countries, Theory, Scoping review Paper type Literature review

\section{Introduction}

Pay-for-performance (P4P) is used in many health systems, both in high-income countries and in low- and middle-income countries (LMICs,) where it is commonly referred to as "performance-based financing" (PBF). Its supporters claim that it can increase the use and improve the efficiency of health services - be it the allocative, technical or dynamic efficiency; address low responsiveness and increase the accountability of health systems; enhance quality of care; increase equity; help address the structural problems plaguing health systems and improve and reform health systems (Eichler, 2006; Eichler et al., 2009; Eldridge and Palmer, 2009; Scheffler, 2010; Maynard, 2012; Meessen et al., 2011).

The authors thank Bruno Boidin, Lara Gautier, Sarah Louart and Bruno Ventelou for their feedback on a previous version of this article.

Funding: EP's and OB's contribution was supported by the ARC grant for Concerted Research Actions, financed by the Wallonia-Brussels Federation.

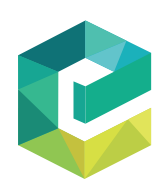

Journal of Health Organization and Management (C) Emerald Publishing Limited $1477-7266$ DOI 10.1108/JHOM-04-2020-0161 
However, $\mathrm{PBF}$ has been subject to fierce debates, and pieces of evidence with regard to its effects in LMICs are mixed. Some studies indicate positive effects in terms of coverage, quality of targeted services and some health outcomes, as well as in terms of strengthening health systems (Basinga et al., 2011; Das et al., 2016; Kandpal, 2017; Suthar et al., 2017; Henrion et al., 2018; Borghi et al., 2018). But a growing volume of literature also points to the high costs, risks and potential unintended and even perverse effects of PBF (Ridde, 2005; Kalk et al., 2010; Kalk, 2011; Ireland et al., 2011; Turcotte-Tremblay et al., 2016, 2017, 2020; Ridde et al., 2018). Some authors have questioned its appropriateness as an effective, efficient and equitable approach. They have argued that its implementation has been rushed, and that it could damage health systems in LMICs (Paul et al., 2018a).

The debate over PBF's suitability is strenuous and full of misunderstandings; it has been cleaved between "pro-" and "anti-PBF" authors (Manitu et al., 2015; Paul and Ridde, 2018). This division is likely due to diverging perceptions about what PBF is all about - from a narrow definition of payments based on output to a comprehensive "... reform package focused on targeted services with many different aspects that go beyond the health worker level" (Renmans et al., 2017b). Moreover, Paul and Renmans suggested that there has been a "... lack of a clear and thorough analytical framework and robust scientific research but also the underutilisation of findings and lessons from other fields of study, other theories, and similar programmes" (Paul and Renmans, 2018).

$\mathrm{PBF}$ is the subject of growing literature that has approached it in various ways, including its political process, design, implementation, effects and impacts. In particular, PBF effects have been assessed in the literature through three different approaches: the impact evaluation of health outcomes (Basinga et al., 2011; Zeng et al., 2018; Lannes et al., 2016; De Walque et al., 2017; Skiles et al., 2015; Engineer et al., 2016; Nimpagaritse et al., 2016; Rajkotia et al., 2017; Binyaruka et al., 2015); perceptions, effects on behavior, motivation, satisfaction and unintended consequences (Turcotte-Tremblay et al., 2017; Paul et al., 2014; Chimhutu et al., 2014, 2016; Lannes, 2015; Aninanya et al., 2016; Bhatnagar and George, 2016; Schuster et al., 2016, 2018; Khim, 2016; Lohmann et al., 2016, 2018a, 2018b; Shen et al., 2017) and, increasingly, evaluations attempting to "open the black box" of PBF and better understand the mechanisms through which it produces effects (Borghi et al., 2018; De Walque et al., 2017; Nimpagaritse et al., 2016; Ssengooba et al., 2012; Renmans et al., 2017a; Paul et al., 2018b; Ridde et al., 2014; Mcmahon et al., 2016; Ogundeji et al., 2016; Alonge et al., 2017; Mabuchi et al., 2018; De Allegri et al., 2018). Recent publications call for a better understanding of the mechanisms underlying PBF's pathway to impact (Borghi et al., 2018; Renmans et al., 2016a). However, the mobilization of theories is essential to ensure a better understanding of the mechanisms at work. A number of studies that aim to develop a better understanding of the theory of change associated with PBF programs are currently underway (Borghi et al., 2018). These studies are particularly concerned with the design of the interventions as planned by the implementers to support evaluations according to the theory-driven evaluation school of thought (Weiss, 1998; Lipsey, 1993), rather than with understanding the theories underlying the potential mechanisms relating to the functioning of PBF. Yet, to date, there are multiple theoretical bases behind PBF. According to an evaluation made on behalf of the Norwegian Development Agency-one of the major PBF donors-there is not only a lack of a consistent explanation as to how and why PBF is supposed to produce results in the first place, but also why it is supposed to produce better results than alternative approaches (Helland and Maestad, 2015; Lindkvist and Bastøe, 2015).

Based on this premise, we wondered on what bases PBF could possibly be justified as a preferred approach. In order to avoid ideological biases-which could have happened if we had limited our analysis to "pro-PBF" handbooks or "con-PBF" papers-we opted for a twotier approach: first, we searched the literature in a broad way, looking for the different theories referred to in the context of the scientific literature on PBF (which, we assumed, are 
less ideologically tainted than program documents, for instance); second, we critically assessed whether some consistent theoretical justification for PBF emerged, making the case for PBF, possibly compared to alternative approaches.

The purpose of this study was to review and understand the theoretical bases utilized to justify the use of PBF in the health sectors in LMICs. We focused on this category of countries because PBF has developed in the health sector in LMICs as an independent approach from existing currents of the literature and government-wide public sector reforms (Paul and Renmans, 2018). Furthermore, researchers interested in P4P tend to group into those working on either high or low- and middle-income countries, with still limited knowledge exchange, potentially constraining opportunities for learning from across other income settings (Anselmi et al., 2020). Therefore, even if theories are presumably not context-specific, it made sense to focus on PBF in LMICs, hypothesizing that these countries shared contextual features that probably justified the choice for PBF. Another reason for limiting ourselves to LMICs was that many of these countries are aid-dependent and, therefore, probably more prone to donors' and other PBF “diffusion entrepreneurs" influence (Gautier et al., 2019b).

\section{Methods and material}

We conducted a scoping review of the scientific and grey literature on PBF in an attempt to identify all the theories that were utilized to underpin PBF. In a second step, we critically analyzed whether there was consistent theoretical justification for resorting to PBF. The literature search was conducted using the five-step scoping framework proposed by Arksey and O’Malley (2005) and improved by Levac et al. (2010) and by Daudt et al. (2013).

\section{Step 1: Identifying the research question}

We explored the following research question: "What are the theories that have been mobilized in the literature to support the utilization of PBF in the health sector in LMICs?" In our review, we defined theory as "... a set of statements about the relationship(s) between two or more concepts or constructs" (Jaccard and Jacoby, 2009). As suggested by Imenda (2014), "Aspects such as 'explaining' and 'making predictions' are among the most common features of the definition of 'theory"' (Imenda, 2014). However, there are different levels of theories that may be mobilized to justify resorting to PBF (Ridde et al., 2020). Here we aligned ourselves with the approach adopted by Kislov et al. (2019) and distinguished between three types of theories:

(1) Grand theories: "All-inclusive systematic efforts to develop a master conceptual scheme, often aspiring to present a unified theory of the social world";

(2) Mid-range theories: "Theories that lie between the working hypotheses that evolve in abundance during day-to-day research and the all-encompassing speculations comprising a master conceptual scheme";

(3) Program theories: “'Small theories' providing a sensible and plausible explanation about how a specific policy, intervention, or project is supposed to function and achieve its objectives" (Kislov et al., 2019). The latter definition was inspired by what Lipsey suggested nearly three decades ago (Lipsey, 1993).

This review focused on grand theories and mid-range theories utilized for supporting the adoption of PBF. It did not explore program theories (or theories of change) with regard to individual PBF schemes. Theories of change are pragmatic tools that are useful for specific program evaluation. Therefore, because there is substantial heterogeneity in the design of PBF schemes in LMICs (Kovacs et al., 2020) and considering that each PBF scheme has its own specificities, theories of change do not allow for sufficient generalizability. 
Our research strategy (laid out in the Appendix) was developed with the assistance of two librarians. Since PBF is at the crossroads between health, economics and management, we searched the following databases: PubMed, Scopus, ProQuest, ECONLit and Business Source Premier (via EBSCO) and Base. The review was conducted in English and French. Since there is no MeSH term corresponding exactly to PBF, we included the following keywords in the research equation (possibly truncated, with appropriate adaptations and with their equivalent in French for the Base search):

(1) "performance-based financing" and related terms;

(2) AND theory and related terms;

(3) AND health and related terms;

(4) AND all related terms corresponding to LMICs, as defined by the World Bank.

\section{Step 3: Study selection}

The forerunner of PBF as it is known today, which was notably promoted by the Health Results and Innovation Trust Fund and now by the Global Financing Facility, was the experience of the contracting of health services as tested in Haiti and Cambodia in 1999 (Fritsche et al., 2014; Eichler et al., 2001). That study date was why we restricted our review to studies published from 1999 onwards.

This scoping study considered studies that met the following inclusion criteria:

(1) To have been published between January 1999 and June 2019;

(2) To have been published in English or French;

(3) To consist of original, published research (including empirical and theoretical studies, study protocols and commentaries);

(4) To be dealing with the health sector;

(5) To concern one or several LMICs as defined by the World Bank (note that we included the countries in the LMIC database as of the Fiscal Year, 2019-2020, but also those of the Fiscal Year, 2018-2019 - see classification available at: https://datahelpdesk. worldbank.org/knowledgebase/articles/906519-world-bank-country-and-lendinggroups);

(6) To concern a performance-based approach that comprises at least financial premiums granted to healthcare providers based on verified pre-determined results;

(7) To use a mid-range or grand theory to explain resorting to PBF;

(8) To have a full text available.

The exclusion criteria were the counterparts. In particular, we rejected studies that were not published research (such as publication reports and vulgarization papers summarizing original research, conference posters and meeting presentations); studies that concerned forms of results-based approaches other than those comprising financial premiums granted to healthcare providers based on verified pre-determined results; and those that used only a conceptual framework, a theory of change or program theory. We included both empirical and non-empirical studies provided they met inclusion criteria.

The search of the scientific databases was launched in July 2019 based on title, abstract and keywords. We identified 269 papers (after removing duplicates), which were subject to double-blind screening by two of the authors (EP and $\mathrm{OB}$ ). Eligibility in terms of the inclusion 
criteria was assessed based on title and abstract and the opinion of the third author (VR) was required in the event of doubt or disagreement (25 papers). A total of 218 papers were excluded, often with multiple reasons for exclusion, especially if they did not deal with LMICs or with performance-based incentives at the healthcare providers' level. Forty-seven additional relevant studies were identified through other sources (screening of the bibliography of existing reviews, search for grey literature through the websites of the World Bank, Health Results and Innovation Trust Fund/Results-Based Financing, World Health Organization, PBF Community of Practice (Google group, Collectivity, SinaHealth) and added manually. Two authors (EP and VR) assessed full-text articles for eligibility: 34 were rejected based on the full text not meeting one or more of the inclusion criteria, and 64 papers were selected for analysis. We rejected a large number of identified studies that did not meet our inclusion criteria because they either contained a theory of change, but not one that rested on a grand or mid-range theory; or because they utilized political or social science theories to explain the diffusion of PBF, but not its functioning or effects.

Figure 1 shows the Preferred Reporting Items for Systematic Reviews and Meta-Analyses (PRISMA) diagram of the study (Tricco et al., 2018).

\section{Step 4: Charting the data}

Selected papers were charted using an Excel spreadsheet. The relevant data was systematically extracted by EP according to a standardized extraction file developed with $\mathrm{OB}$ and VR. It contained the following criteria:
Theories of PBF in LMICs

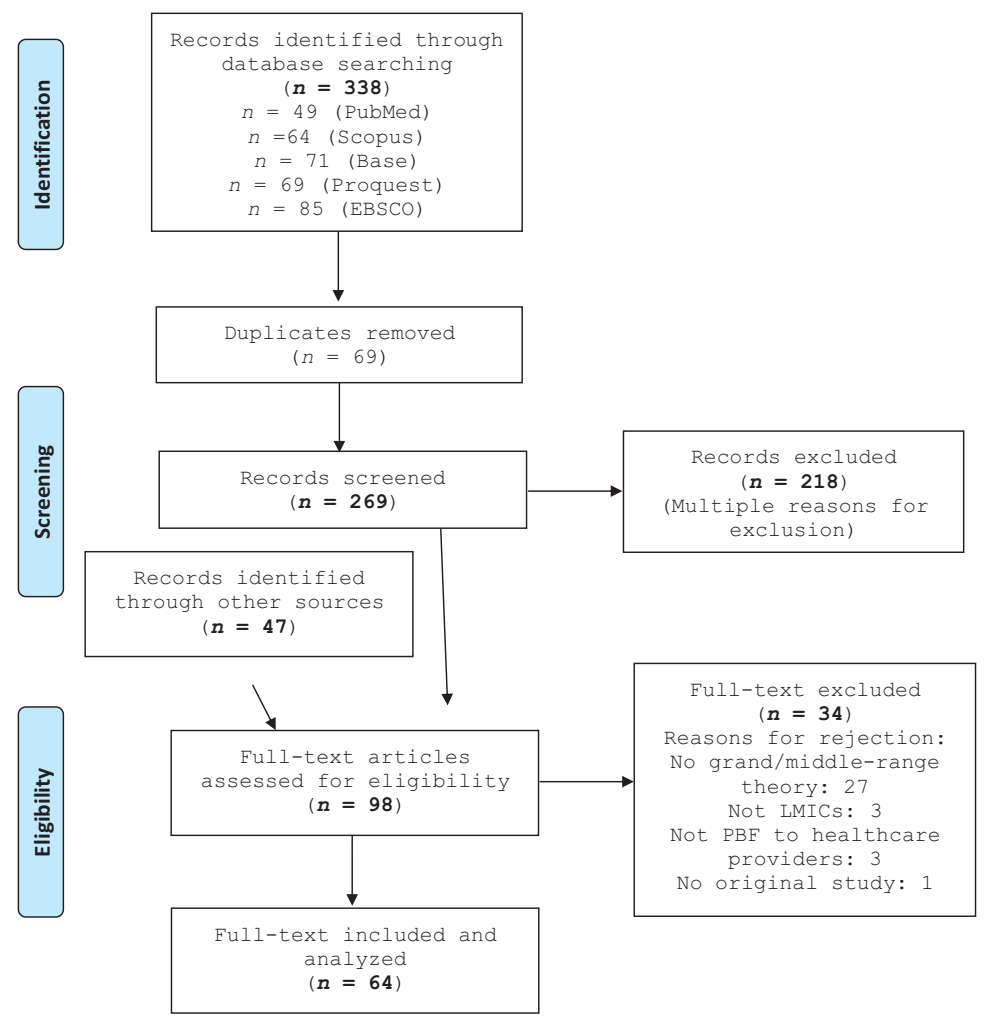

Figure 1. PRISMA flow chart 
(1) General information on the study;

(2) Three criteria relative to the nature (empirical or non-empirical) of the study, whether it was peer-reviewed or not and whether or not it was independent of an organization promoting or financing PBF (as a proxy from free from conflict of interest);

(3) The possible focus country/ies of the study;

(4) Whether the study developed a theory of change (or an program theory);

(5) The grand or mid-range theory/ies resorted to;

(6) Other analytical elements.

\section{Step 5: Collating, summarizing and reporting the results}

The last step of this scoping review consisted of a comprehensive analysis of the theoretical bases of PBF. To do so, all included articles were subject to direct content analysis (Patton, 2002). EP reviewed, highlighted and coded all the papers that mentioned one or more theories used to support PBF. EP coded using an evolving coding sheet so we could keep an inventory all the utilized theories. All the text relative to each theory were then sorted and synthetized. The analysis was shared and discussed with $\mathrm{OB}$ and VR.

\section{Results}

Overview of the studies included

Table 1 presents an overview of the characteristics of the included studies.

Of the 64 studies included, $43(67 \%)$ were empirical; 39 (61\%) were peer-reviewed, and 39 $(61 \%)$ were independent (free from conflicts of interest). Countries most commonly represented (out of 33 studies that are focused on one or more countries) were Tanzania (4 studies) followed by Cambodia, Democratic Republic of Congo, Malawi, Mozambique and Nigeria (3 studies each).

\section{Theories utilized to support PBF}

The grand and mid-range theories behind PBF are synthetized in Table 2.

Economic theories. PBF was supported predominantly by economic theories. Only 12 out of the 64 papers included in our study $(19 \%)$ did not explicitly refer to one or more economic theories. Overall, the principal-agent theory (in the neo-institutional sense) was the most commonly used theory, explicitly referred to in 41 studies $(64 \%)$. Other economic theories closely related to, or considered similar by some authors, to the principal-agent theory were also referenced: contract theory (in 10 studies), incentive theory (broadly speaking) (10 studies), new institutional economics (5 studies) and property rights theory (3 studies). Behavioral economics was referred to in nine studies, and various neoclassical theories were also used, notably public choice theory ( 3 studies). However, a majority of the studies included in this review just mentioned economic theories, without explaining how they were supposed to support PBF (or not). For a better understanding of economic theories, and how they can be utilized to support PBF, refer to the $\mathrm{PhD}$ thesis of Meessen (2009).

The economic theories used three broad sets of arguments to support PBF - even if the frontier between the various approaches were blurred (Meessen, 2009). First, neoclassical economics focused on interactions between supply of, and demand for, health services and argued that encouraging competition between healthcare providers would foster efficiency. Second, the various theories akin to new institutional economics focused on the norms and rules (institutions) that shape stakeholders' behavior and interactions - and hence determine 


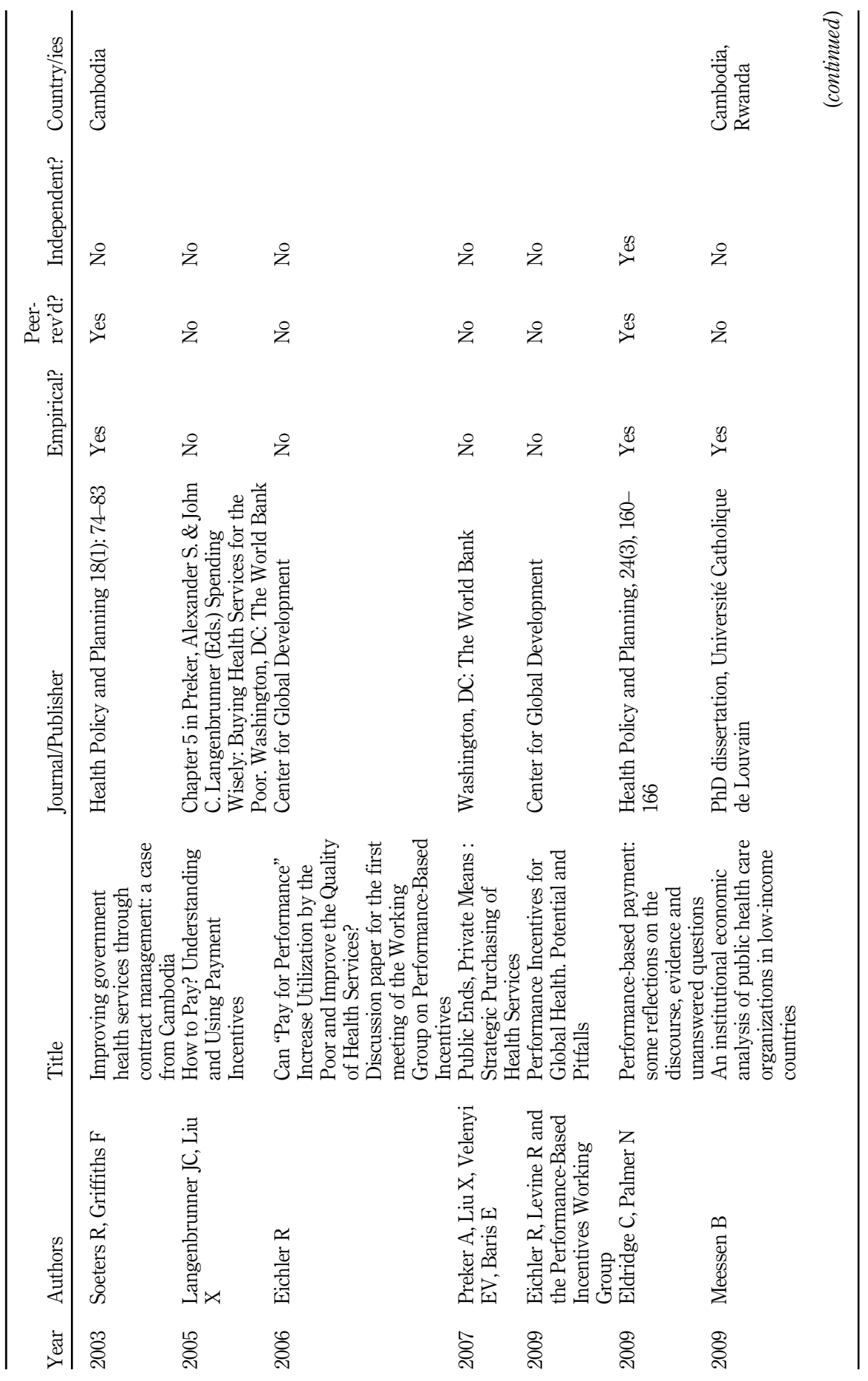
Theories of
PBF in LMICs

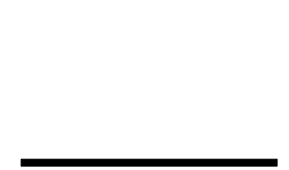

Table 1.

Description of included studies 

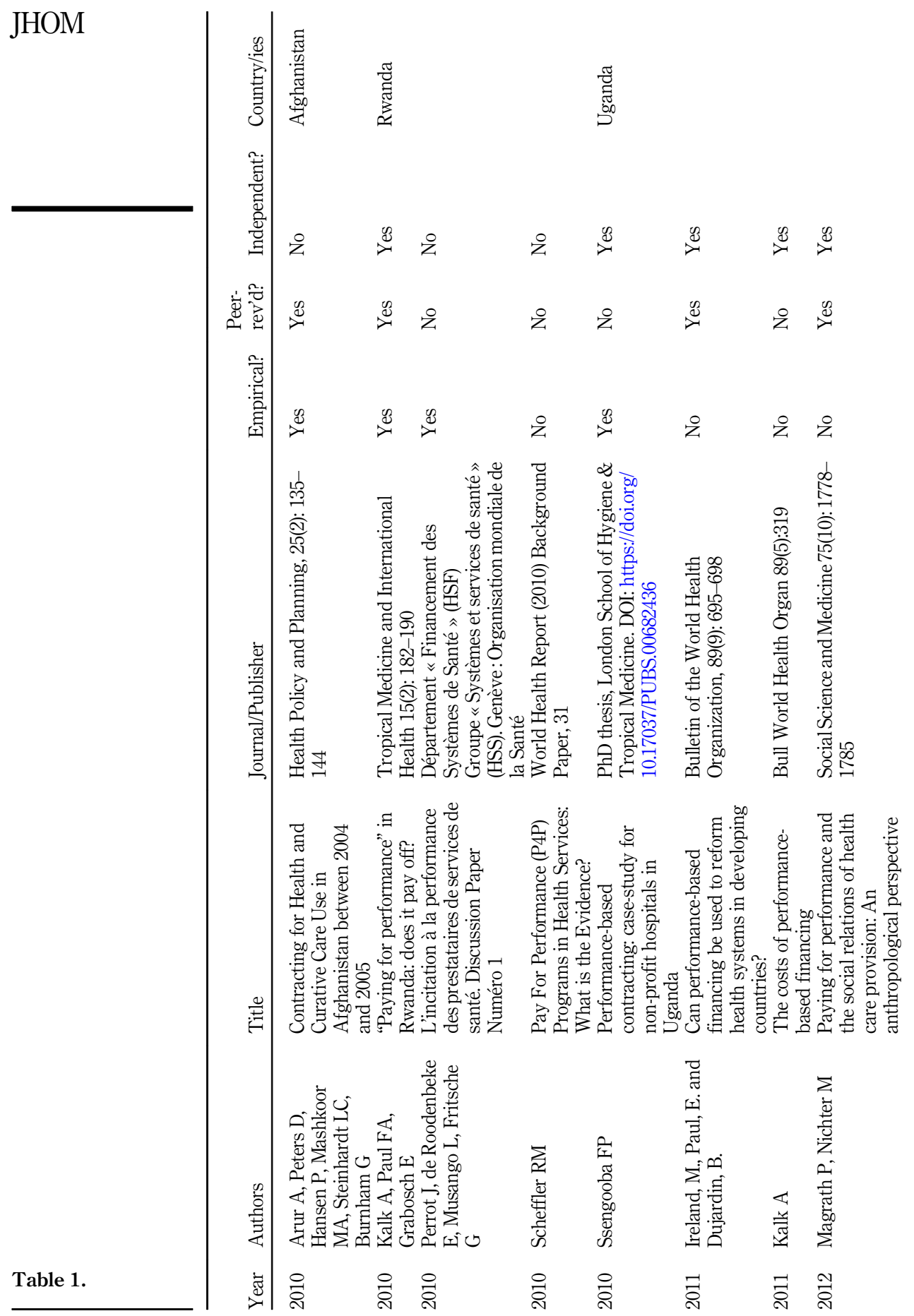

Table 1. 


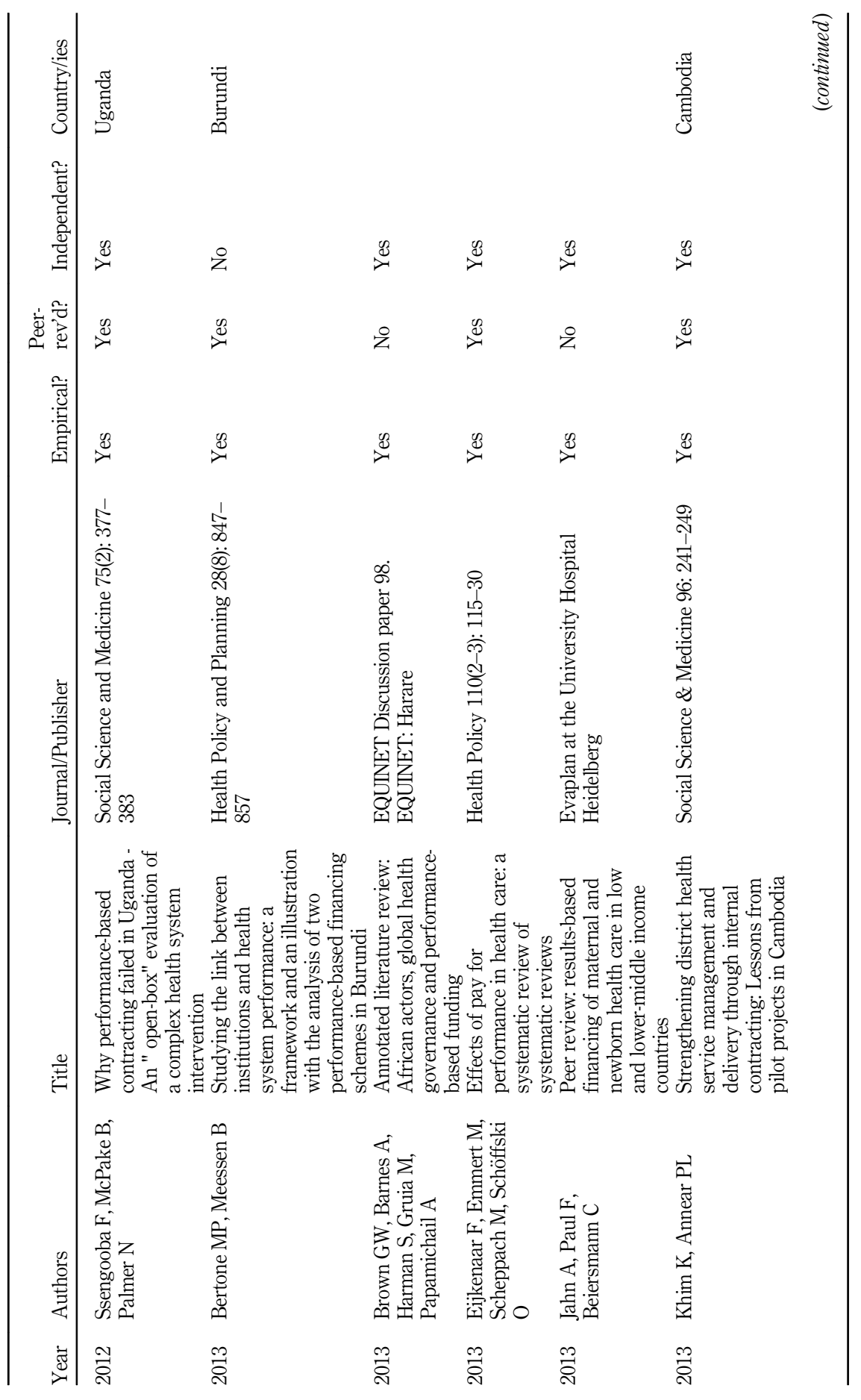

Theories of PBF in LMICs 


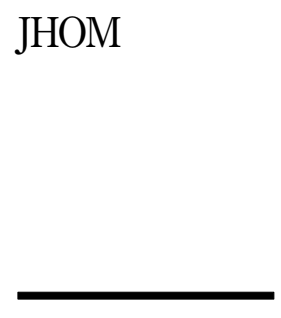

Table 1.

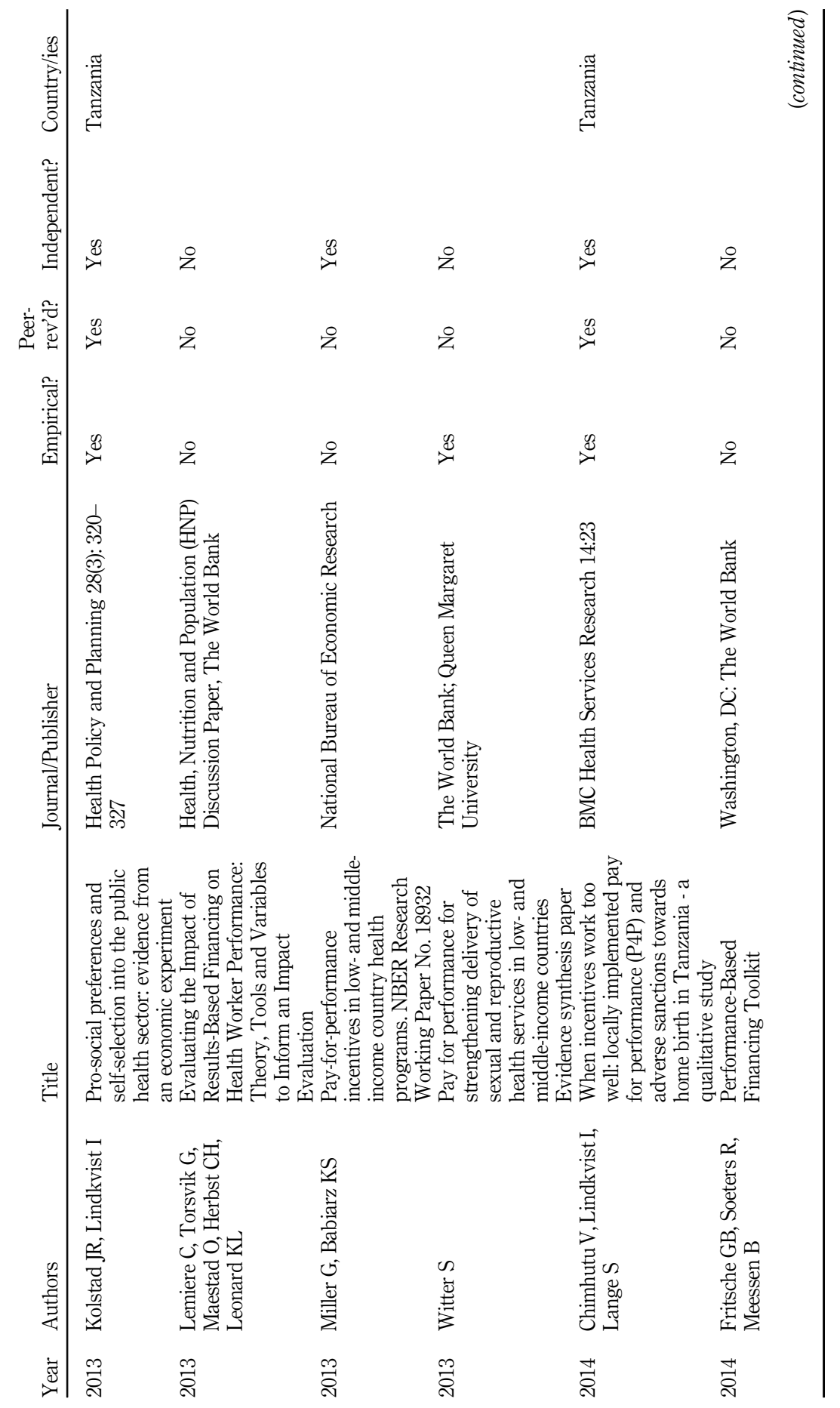




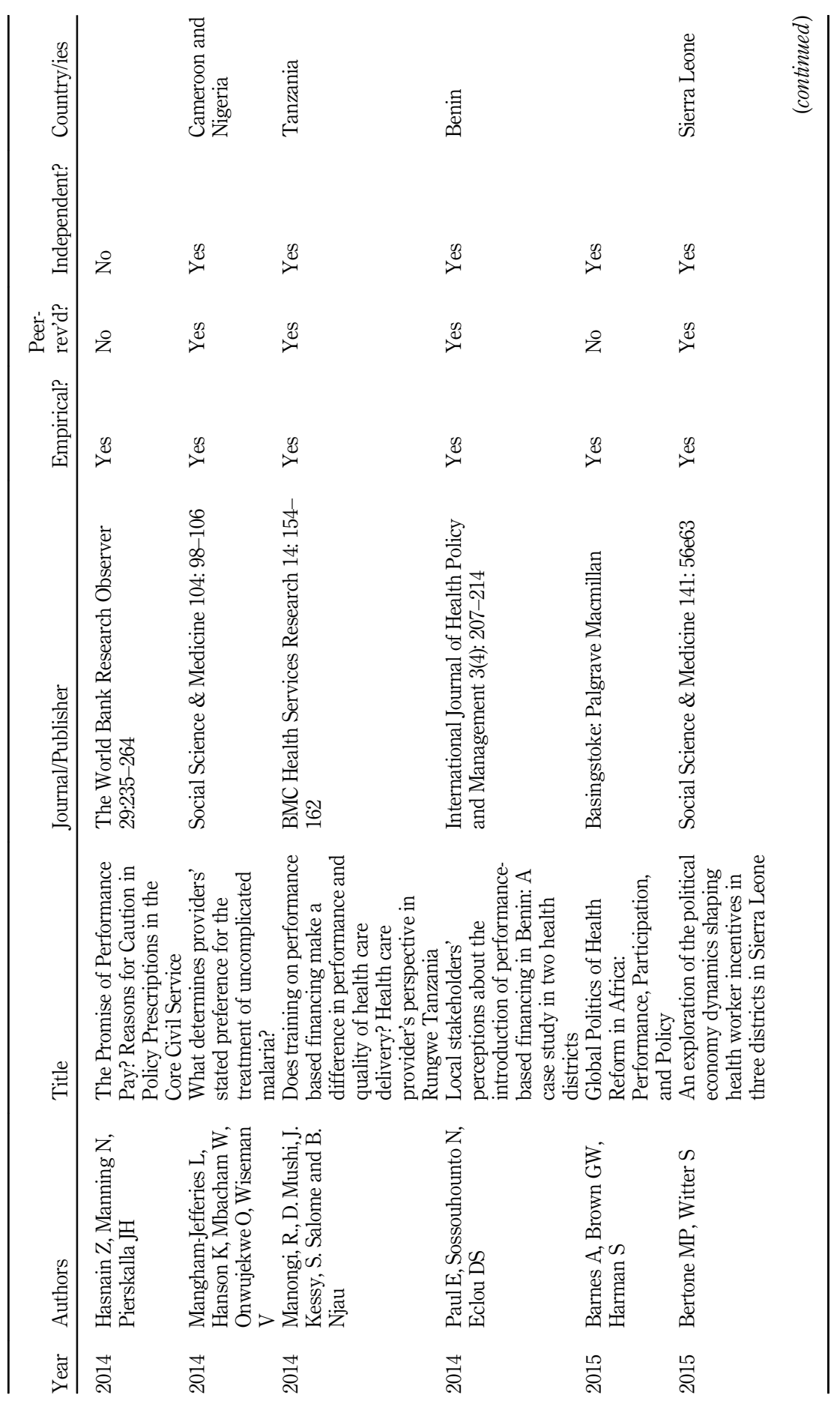

Theories of PBF in LMICs 

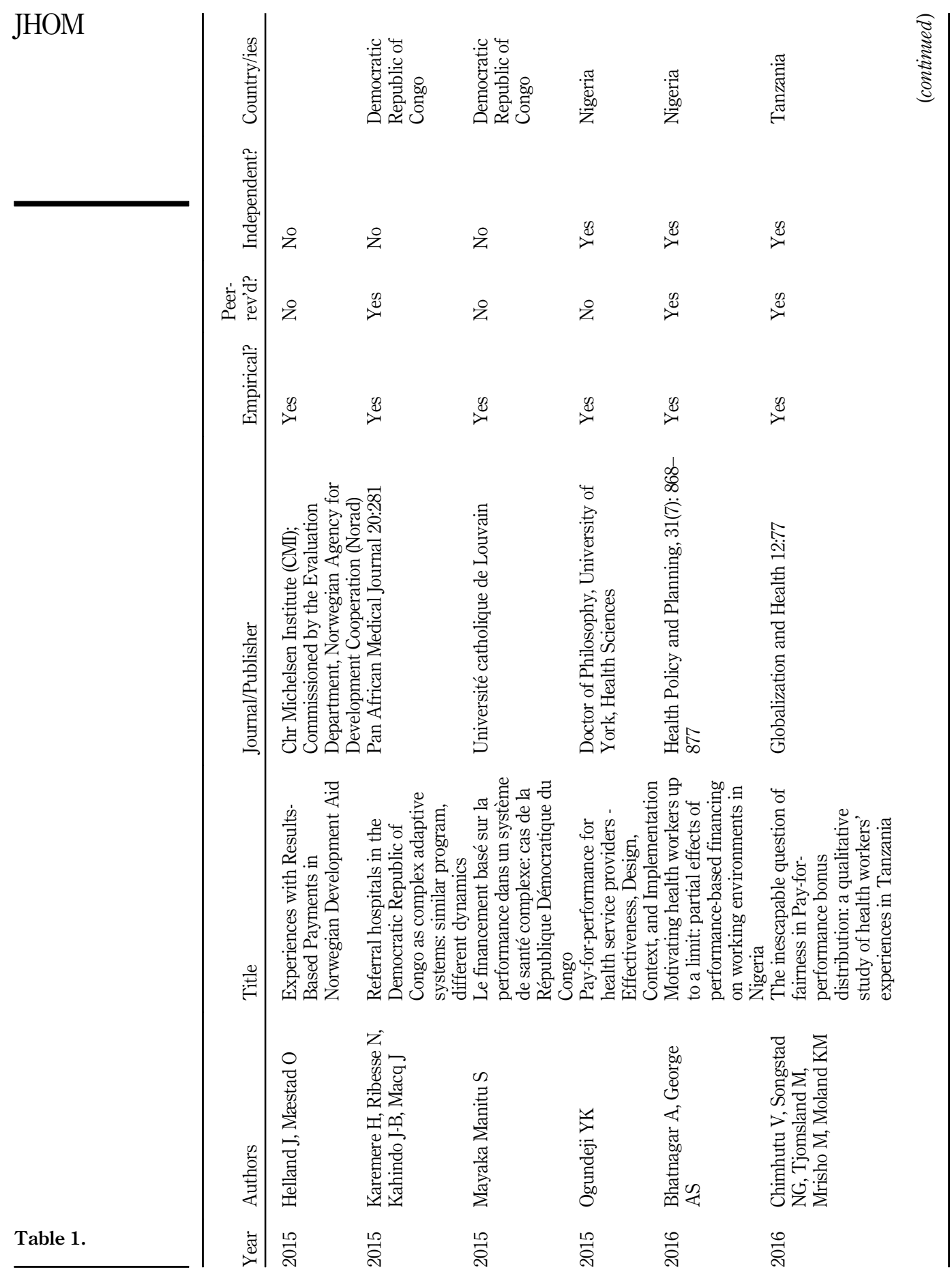


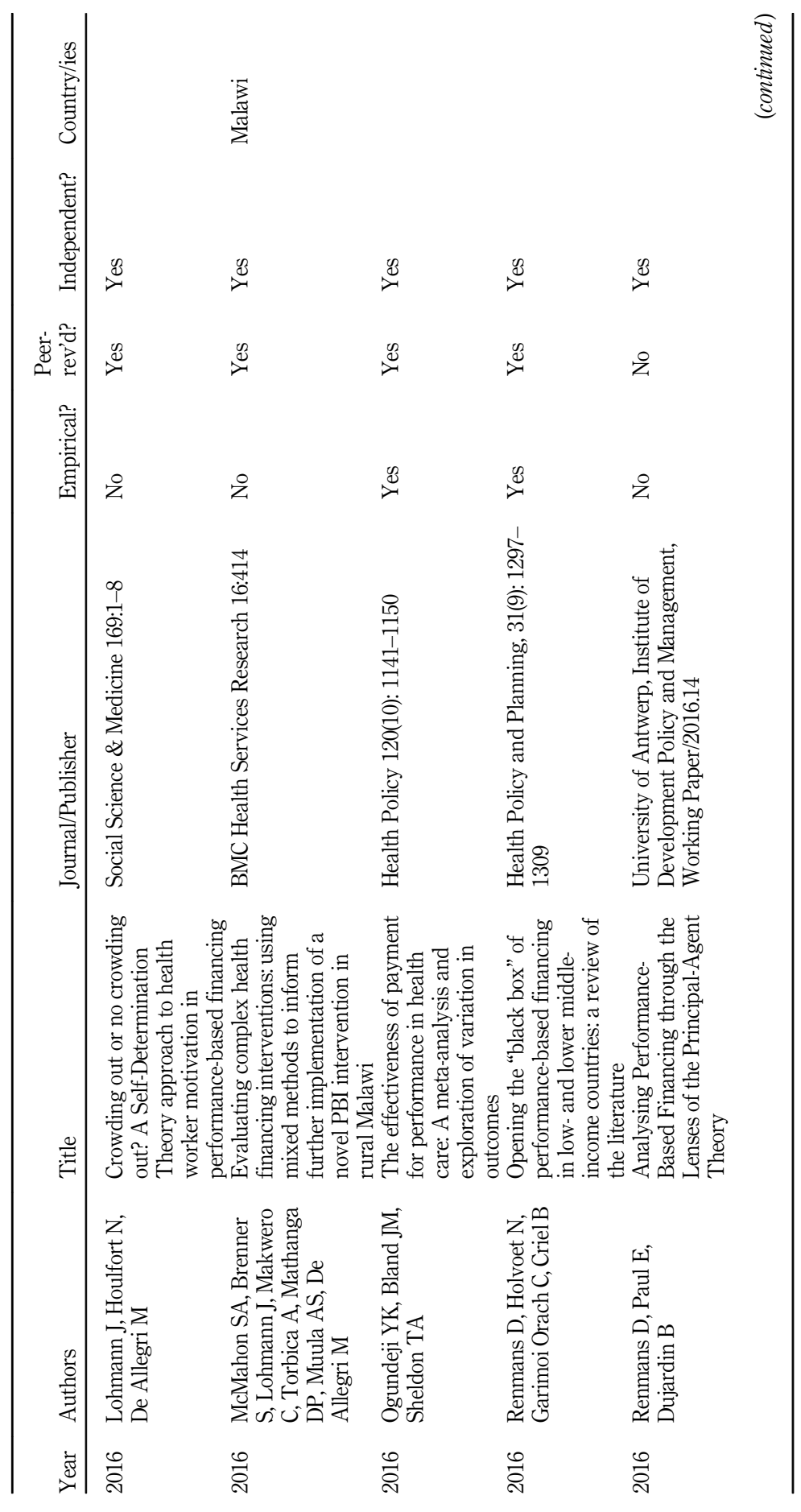

Theories of $\mathrm{PBF}$ in LMICs 

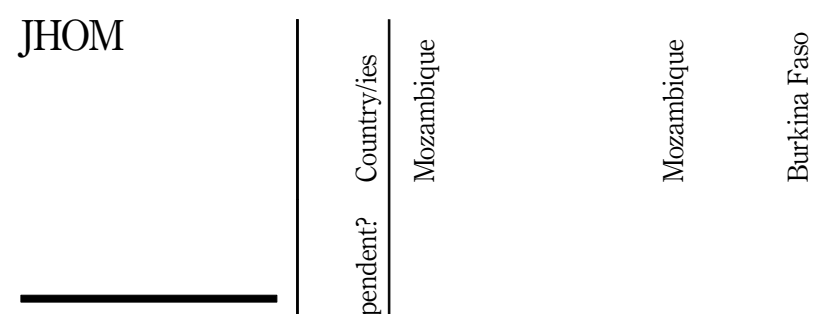

茫

z

$\underset{x}{3}$

ํㅜㄴ

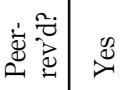

$\stackrel{\infty}{*} \quad \approx$

zำ

$\stackrel{2}{2}$

氖

$\sqrt{2}$

$\stackrel{\infty}{\infty}$

$\approx$

2

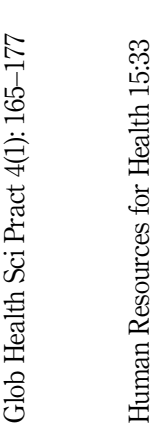

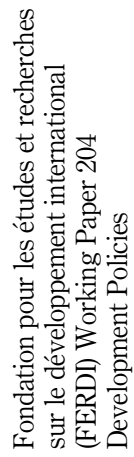

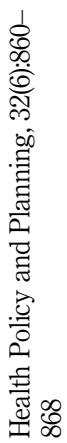

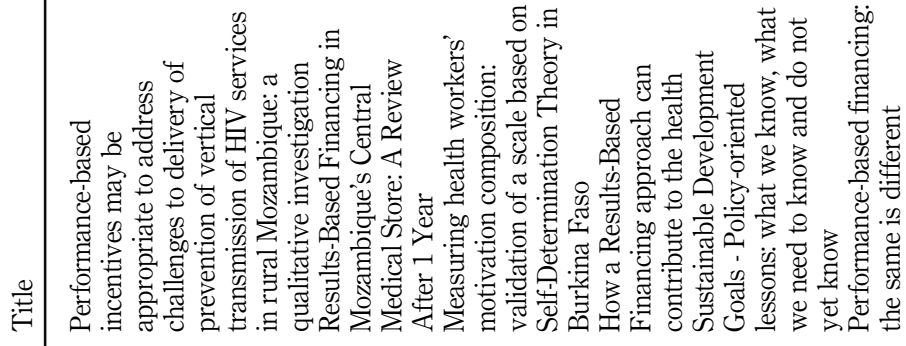
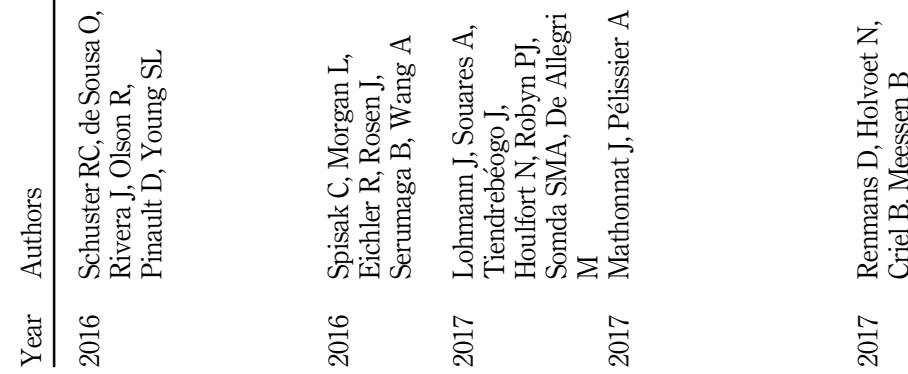

Table 1. 


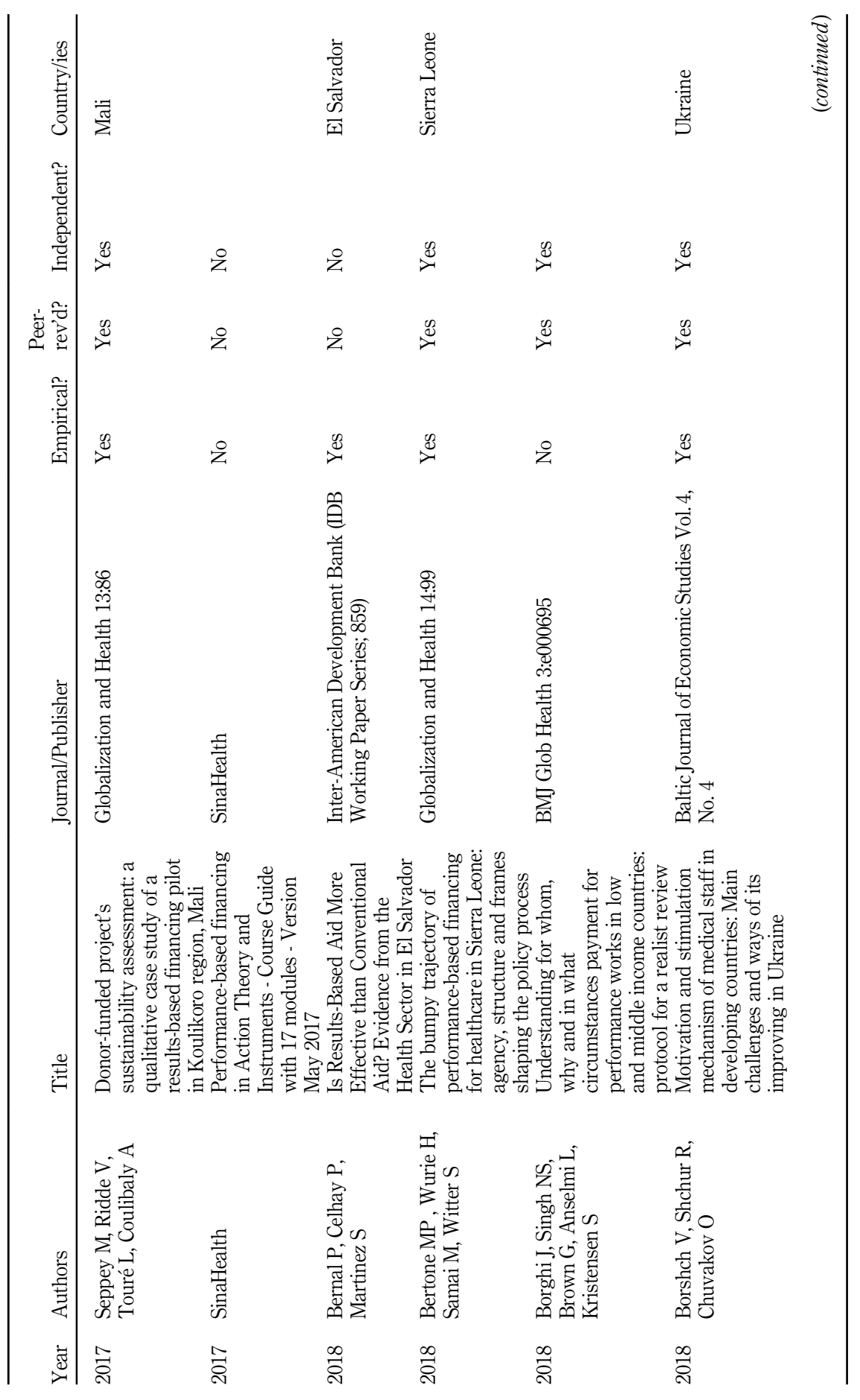

Theories of PBF in LMICs 


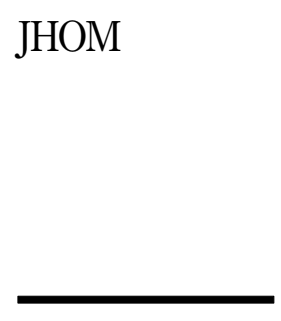

Table 1.

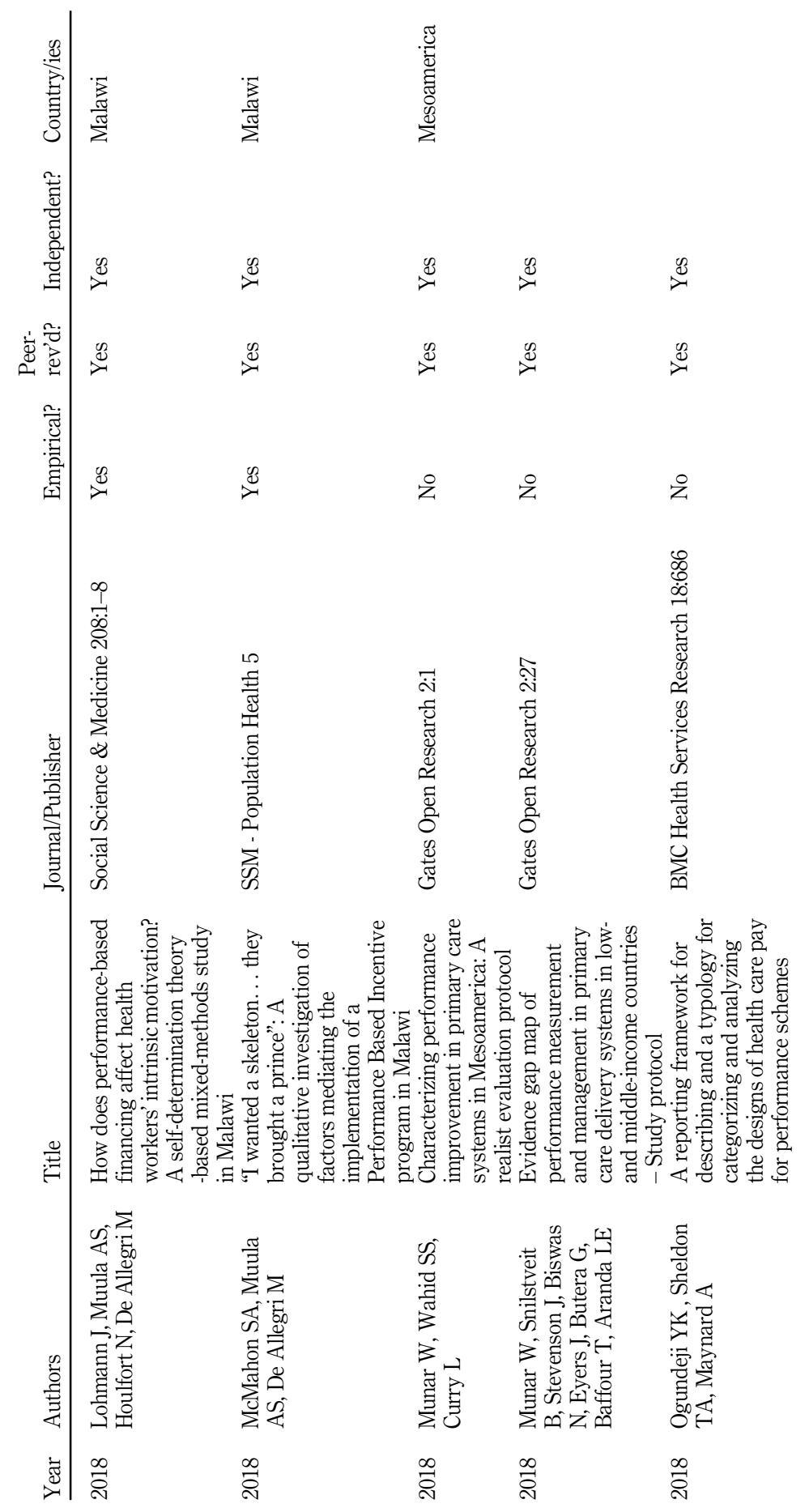




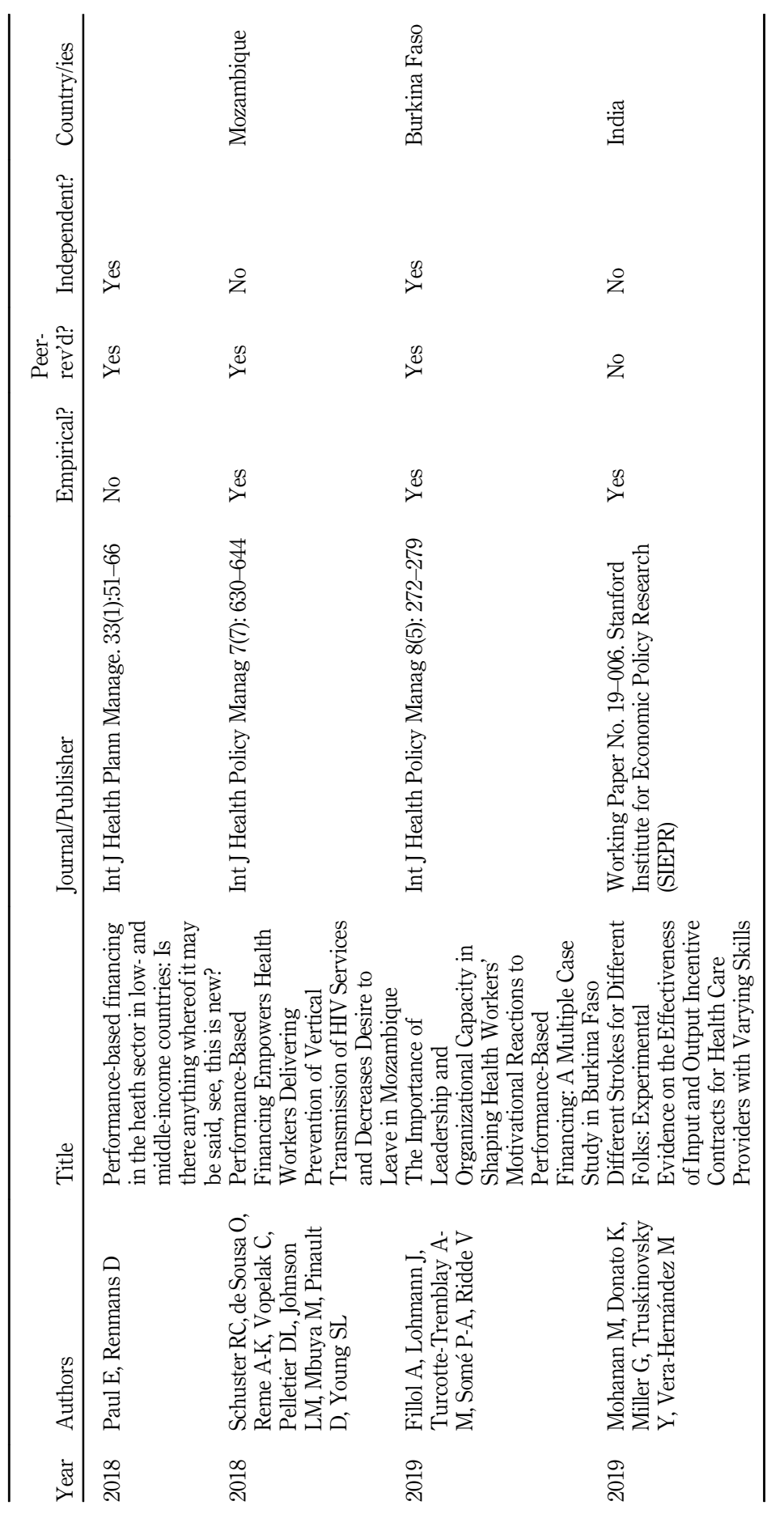

Theories of PBF in LMICs 
Eichler (2006)

Preker et al. (2007)

Eichler et al. (2009)

Meessen (2009)

Arur et al. (2010)

Kalk et al. (2010)

Perrot et al. (2010)

Ssengooba (2010)

Magrath and Nichter (2012)

Bertone and Meessen

(2013)

Brown et al. (2013)

Jahn et al. (2013)

Khim and Annear (2013)

Kolstad and Lindkvist

(2013)

Lemière et al. (2013)

Miller and Babiarz (2013)

Witter (2013)

Chimhutu et al. (2014)

Hasnain et al. (2014)

Mangham-Jefferies et al.

(2014)

Manongi et al. (2014)

Paul et al. (2014)

Barnes et al. (2015)

Bertone and Witter (2015)

Helland and Mæstad (2015)

Mayaka Manitu (2015)

Ogundeji (2015)

Bhatnagar and George (2016)

Chimhutu et al. (2016)

Lohmann et al. (2016)

Mcmahon et al. (2016)

Renmans et al. (2016a)

Renmans et al. (2016b)

Mathonnat and Pélissier

(2017)

Sinahealth (2017)

Bernal et al. (2018)

Munar et al. (2018)

Paul and Renmans (2018)

Schuster et al. (2018)

Mohanan et al. (2019)

Other neo-institutional economic theories 
Theories utilized to support PBF

Contract theory (complete and/or incomplete contract theory)
Referred to by

Preker et al. (2007)

Eldridge and Palmer (2009)

Meessen (2009)

Bertone and Meessen

(2013)

Miller and Babiarz (2013)

Hasnain et al. (2014)

Manongi et al. (2014)

Mayaka Manitu (2015)

Mathonnat and Pélissier (2017)

Transaction costs theory

Property right theory

Incentive theory (undefined)

Free rider theory

Game theory

Sinahealth (2017)

Meessen (2009)

Ssengooba (2010)

Meessen (2009)

Ssengooba (2010)

Bertone and Meessen

(2013)

Eichler et al. (2009)

Scheffler (2010)

Ssengooba (2010)

Ireland et al. (2011)

Bertone and Meessen

(2013)

Hasnain et al. (2014)

Manongi et al. (2014)

Paul et al. (2014)

Ogundeji (2015)

Mohanan et al. (2019)

Ogundeji (2015)

Meessen (2009)

Kolstad and Lindkvist

(2013)

\section{Behavioral economics}

Broadly speaking

Preker et al. (2007)

Lemière et al. (2013)

Witter (2013)

Hasnain et al. (2014)

Ogundeji (2015)

Renmans et al. (2016a, b)

Mathonnat and Pélissier

(2017)

Loss aversion theory

Renmans et al. (2017a, b)

Ogundeji (2015)

Ogundeji et al. (2018)

Theory of human behaviors: homo oeconomicus

Meessen (2009)

Neoclassical economic theories

Public choice theory

Soeters and Griffiths (2003)

Fritsche et al. (2014)

Sinahealth (2017) 
Theories utilized to support PBF

Monopolistic competitive models

Determinants of demand and supply

Free markets principles

Supplier-induced demand

Grossman theory of demand

Rational choice theory

Wage fairness theory

Random utility theory

Economic theory (undefined)

\section{Referred to by}

Langenbrunner and Liu (2005)

Eichler (2006)

Sinahealth (2017)

Ogundeji et al. (2016)

Borghi et al. (2018)

Magrath and Nichter (2012)

Munar et al. (2018)

Fritsche et al. (2014)

Mangham-Jefferies et al. (2014)

Eijkenaar et al. (2013)

Ogundeji et al. (2018)

Psychological theories

Motivation(al) theories (undefined / broadly speaking)

Crowding-out theory

Herzberg's two-factor theory

Expectancy theory

Needs theory

Self-efficacy theory

Instrumentality theory

Reactance theory

Equity theory

Social learning theory

Attribution theory

Role model theory

Reinforcement theory
Preker et al. (2007)

Ssengooba (2010)

Hasnain et al. (2014)

Chimhutu et al. (2016)

Spisak et al. (2016)

Sinahealth (2017)

Borghi et al. (2018)

Kalk (2011)

Jahn et al. (2013)

Kolstad and Lindkvist

(2013)

Lemière et al. (2013)

Renmans et al. (2016)

Mathonnat and Pélissier

(2017)

Brown et al. (2013)

Fritsche et al. (2014)

Preker et al. (2007)

Ssengooba (2010)

Magrath and Nichter (2012)

Ssengooba et al. (2012)

Brown et al. (2013)

Hasnain et al. (2014)

Ogundeji (2015)

Mcmahon et al. (2018)

Ogundeji et al. (2018)

Preker et al. (2007)

Fritsche et al. (2014)

Bhatnagar and George

(2016)

Preker et al. (2007)

Munar et al. (2018)

Preker et al. (2007)

Preker et al. (2007)

Preker et al. (2007)

Preker et al. (2007)

Preker et al. (2007)

Preker et al. (2007)

Magrath and Nichter (2012)

Hasnain et al. (2014)
Jahn et al. (2013)

Table 2. 
Theories utilized to support PBF

Evaluability theory

Justifiability theory

Risk aversion theory

Goal (gradient / setting) theory

Mental accounting theory

Cognitive evaluation theory

Social cognitive theory

Referent cognitions theory

Self-determination theory
Referred to by

Ogundeji (2015)

Ogundeji et al. (2018)

Ogundeji (2015)

Ogundeji (2015)

Ogundeji et al. (2018)

Preker et al. (2007)

Ogundeji (2015)

Munar et al. (2018)

Ogundeji et al. (2018)

Ogundeji (2015)

Ogundeji et al. (2018)

Bhatnagar and George

(2016)

Renmans et al. (2017a, b)

Mcmahon et al. (2016)

Chimhutu et al. (2016)

Bhatnagar and George

(2016)

Lohmann et al. $(2016,2017)$

Seppey et al. (2017)

Lohmann et al. (2018)

Munar et al. (2018)

Fillol et al. (2019)

Target income theory

Management / Organizational theories

Organizational theory (undefined)

Magrath and Nichter (2012)

Brown et al. (2013)

Ogundeji et al. (2016)

Sinahealth (2017)

Munar et al. (2018)

Ogundeji et al. (2018)

Contingency theory

Brown et al. (2013)

Barnes et al. (2015)

New Public Management

Ssengooba (2010)

Mathonnat and Pélissier

(2017)

Renmans et al. (2017)

Munar et al. (2018)

Relational signaling theory

Perrot et al. (2010)

"Relational" contracts

Khim and Annear (2013)

Human capital theory

Kolstad and Lindkvist

(2013)

Stakeholder theory (e.g. accountability theories)

The motivation-opportunity-ability framework (grounded in human resources and

Munar et al. (2018)

Schuster et al. (2016)

Schuster et al. (2018)

Good governance

Sinahealth (2017)

Sinahealth (2017)

Decentralization

\section{Political/Social science theories}

Social science theory (broadly speaking)

Political science (broadly speaking)

Management theory (broadly speaking))

Political economy

Magrath and Nichter (2012)

Brown et al. (2013)

Renmans et al. (2017a, b)

Munar et al. (2018)

Borshch et al. (2018)

Bertone et al. (2018) 


\begin{tabular}{|c|c|}
\hline Theories utilized to support PBF & Referred to by \\
\hline Bourdieu "habitus" theory & Magrath and Nichter (2012) \\
\hline Social learning & Renmans et al. $(2017 \mathrm{a}, \mathrm{b})$ \\
\hline Sociological de-professionalization theory & Brown et al. (2013) \\
\hline $\begin{array}{l}\text { Distributive justice; procedural justice ("perceptions of the fairness of decision-making } \\
\text { processes") }\end{array}$ & Chimhutu et al. (2016) \\
\hline Interpretive policy analysis & Bertone et al. (2018) \\
\hline \multicolumn{2}{|l|}{ Other theories } \\
\hline \multirow[t]{3}{*}{ Intervention / implementation theories } & Ssengooba (2010) \\
\hline & Mcmahon et al. (2018) \\
\hline & Munar et al. (2018) \\
\hline \multirow[t]{3}{*}{ Complexity theory } & Ssengooba (2010) \\
\hline & Ssengooba et al. (2012) \\
\hline & Brown et al. (2013) \\
\hline \multirow[t]{4}{*}{ ((Complex) Adaptive) Systems theory / analysis (+Cybernetics-systems theory) } & Barnes et al. (2015) \\
\hline & Karemere et al. (2015) \\
\hline & Sinahealth (2017) \\
\hline & Munar et al. (2018) \\
\hline Ecologically embedded determinants of performance & Schuster et al. (2016) \\
\hline Social-ecological model & Mcmahon et al. (2018) \\
\hline Public health (e.g. patient-centered care) & Renmans et al. (2017a) \\
\hline Educational sciences (e.g. transformative learning) & Renmans et al. $(2017 \mathrm{~b})$ \\
\hline Evaluation use theory & Munar et al. (2018) \\
\hline
\end{tabular}

Table 2.

economic performance - in the presence of information asymmetry between stakeholders. They argued that considering a number of assumptions regarding, for example, the distribution of property rights, contractual relationships, agency costs or transaction costs, PBF could be the optimal institutional design. Third, behavioral economics also adopted a "micro" perspective and introduced lessons from psychology to study how individuals take decisions. It argued that PBF could potentially provide the right incentives to increase healthcare providers' motivation, but that it could, perhaps, induce perverse behavioral responses.

Psychological theories. Psychological theories were utilized by 28 studies (45\% of those included in this review). Many referred to a wide array of motivation theories, including self-determination theory (8 studies), expectancy theory (8), crowding-out theory (7), cognitive evaluation theory (4), goal (-setting, -gradient) theory (4), needs theory (3), Herzberg's two-factor theory (3) and self-efficacy theory (2). Other organizational psychological theories included social cognitive theory, mental accounting theory and justifiability theory. For more information on behavioral economics and psychological theories, refer to the work of Ogundedji (2015), Ogundeji et al. (2018).

However, once again, many studies included in this review just alluded to psychological theories, or utilized them within an analytical framework or theory of change of PBF (Lohmann et al., 2016, 2018a, 2018b; Mcmahon et al., 2016, 2018), but did not utilize these theories to support or legitimize the choice of PBF as the preferred approach. On the contrary, several studies resorted to psychological theories to warn against possible adverse effects (e.g. motivation crowding-out) of PBF (Kalk, 2011; Jahn et al., 2013; Kolstad and Lindkvist, 2013).

Management/organizational theories. A lesser number of studies (13, or 20\%) supported PBF based on management and organizational theories. However, such studies were generally quite vague and spoke of organizational theory, new public management, or 
management theory in the broad sense, without ever citing arguments specific to these theoretical approaches.

Political and social science theories. Only seven papers (11\% of the included studies) referred explicitly to political and/or social science theories. Nevertheless, political science was predominantly used to study the emergence or diffusion of PBF (which was not the objective of our paper) and not to explain or support its utilization.

Other theories. Finally, 13 papers referred to various other theories, in particular complexity theory and/or systems theory (7) and implementation theories (4).

\section{Interpretation and discussion}

In this section, we complement the factual, non-judgmental results from the literature review by a critical analysis of whether the theories referred to actually support the use of PBF as a preferred approach.

\section{A field dominated by economic theories}

Our results show that $81 \%$ of the included studies introduced economic theories to support PBF. This prevalence may be due to the predominance of economists in the promotion of health financing reforms, including the diffusion of PBF (Gautier et al., 2018; Lee and Goodman, 2002). It should also be noted that behavioral economics and, to a lesser extent, neoinstitutional economic theories, are very much influenced by psychological theories (Meessen, 2009), which were also used to analyze PBF.

\section{An abundance of - and lack of coherence between - theories}

As pointed out by other reviews, an abundance of often overlapping theories from various disciplines have been utilized to support PBF be it all the theories akin to New Institutional Economics (agency theory, incentive theory, contracts theory, etc.) to the wide ranges of behavioral theories (Meessen, 2009; Jahn et al., 2013; Hasnain et al., 2014; Munar et al., 2018; Ogundeji, 2015; Brown et al., 2013; Renmans et al., 2017b). For instance, the PBF training course handbook published by SinaHealth - whose 80th course was delivered in November 2019 - asserted that "PBF draws from microeconomics, systems analysis, public choice and new institutional economics theories". The various "theories underlying PBF and good governance" which it identified were systems analysis; motivation of stakeholders and public choice theory; new public management and contract theory (based on the principal-agent theory); micro-economics and free market principles; and good governance and decentralization (Sinahealth, 2017). However, it is not clear how these different theories work together.

The psychological theories referred to in the literature offered different explanatory frameworks, some of which are continuously evolving. For instance, the so-called "crowdingout theory" has evolved into self-determination theory (Lohmann et al., 2016). Moreover, some papers referred to fragments of a psychological theory but overlooked other fundamental aspects of the theory.

Overall, the abundance of theories utilized to support PBF might leave the reader of our scoping review confused. This confusion is especially the case because some theories contradict each other. For instance, the competitive market theory - which is no longer supported by many economists - is often not compatible with the behavioral economics framework, which relies on bounded rationality of agents and a general skepticism with regard to market forces; and the self-determination theory posits other assumptions on human motivation than the cognitive evaluation theory. Furthermore, some authors tend to blur the lines between various theories (for instance, by equating "contract theory" to 
"incentive theory" without deepening our understanding of what they involve (Manongi et al., 2014), or by referring to "expectations theory" - which is used in relation to interest rates instead of "expectancy theory" - which is a theory of motivation (Magrath and Nichter, 2012)). However, consensus within a given scientific community is one of the major criteria for strengthening the validity of a proposed theory (Jaccard and Jacoby, 2009).

In other types of health interventions (e.g. community mobilization (Gram et al., 2019), knowledge transfer (Scott et al., 2019), health promotion (Breton and De Leeuw, 2011), vector-borne diseases (Degroote et al., 2018)) or research (e.g. health systems (Walt et al., 2008), public policy implementation (Saetren, 2014) and implementation science (Birken et al., 2017)) it is the scarcity of utilized theories that is of concern to analysts. In the case of $\mathrm{PBF}$, by contrast, the abundance of theories may be confusing and indicate that the incentive effects of PBF are very complex (see below). Such an abundance may also be due to the fact that PBF has been mostly supported by economic theories, and the field of economics is characterized by a lack of consensus, numerous theoretical disagreements and strong disconnection between "orthodox" theories and reality (Lawson, 1997). This is also perhaps because PBF is mostly supported by neoliberal ideas and beliefs (Dardot and Laval, 2010), which political scientists have shown to be important in the emergence of a public policy (Béland and Cox, 2011).

\section{Do the theories really support PBF?}

Perhaps due to the wide scope of the literature search process, many of the studies included in this review did not aim to explain or legitimize PBF and just alluded superficially to generic economic, psychological or organizational theories without taking their full measure. It is unclear whether or not the authors used the theories to back PBF. Therefore, we conducted a critical analysis of few studies that were really aimed at justifying PBF and concluded that the theoretical justifications of $\mathrm{PBF}$ as a preferred approach remained unclear and insufficiently supported by convincing argumentation (not to mention empirical evidence, which is out of the scope of this study). For instance, a systematic review of the effects of PBF in healthcare stated that "Both economic theory and common sense support the notion that payment for health care should be determined, at least in part, based on meaningful indicators of quality or value" [1] (Eijkenaar et al., 2013). Another paper stated that PBF "is predicated on the theory that a combination of carrot and stick-i.e. shared financial incentives, plus increased accountability for results - will spur changes in behavior" (Spisak et al., 2016).

The one theory mostly referred to for supporting PBF was the principal-agent theory, which emerged in the 1970s as a refinement of neo-classical economics (Laffont and Martimort, 2002; Renmans et al., 2016b). Principal-agent theory tackles the so-called "agency" problems emanating from diverging interests and information asymmetry between one (or several) agent(s), who perform(s) tasks on behalf of another party (the principal). The relationship between agents and principals is traditionally spelled out in a menu of contracts specifying notably the remuneration to be granted to agents, generally partly based on the output produced. The fundamental agency problem stems from the privately-informed party (the agent) taking an unfair advantage of his/her superior information for his/her own benefit. The principal-agent theory is applied through models searching for contracts that minimize the agency costs due to informational asymmetry between stakeholders, either by providing the agent with the right incentives (for instance, performance premiums) and inducing him/her to behave in the principal's interests, or through an appropriate system of sanctions. It is often optimal for the principal to rely on both types of incentive (Laffont and Martimort, 2002; Paul, 2006). PBF can easily be analyzed through the lenses of the principal-agent theory, since a donor, government, or purchasing agency can be viewed as a 
principal who delegates tasks to a health facility or to its health workers, who are thus viewed as agents (Renmans et al., 2016b).

Many studies included in this review claimed that the principal-agent theory justified PBF. For instance, Eichler and Levine asserted (page 18) that "The classic solution is for the principal to introduce financial rewards and penalties to create incentives for the agent to adopt particular behaviors, with independent monitoring as a necessary adjunct". They nevertheless recognized that "Because it is impossible to specify every desired element of service delivery or behavior, and the most important intangibles of provider-patient interactions cannot be monitored at reasonable cost, contract design implies identifying proxy measures that both can be monitored and represent a collection of good behaviors. Contract design also must guard against unintended consequences" (Eichler et al., 2009).

The basic principal-agent models rest on simplistic, unrealistic assumptions such as considering agents as risk-neutral and as pure homo economicus (Meessen, 2009), disregarding other sources of motivation such as a sense of public service, desire for recognition (reputation), or intrinsic motivation (Paul and Robinson, 2007); having a unique or aggregate measure of output, observable at no cost and without "noise" or measurement incertitude; outputs being to a great extent dependent on agents' efforts and capabilities. More elaborate models have also been developed - see Laffont and Martimort (2002) for an overview of possible variations of the principal-agent model (Laffont and Martimort, 2002). This development enabled researchers to introduce more realistic assumptions - notably so as to take account of the multiplicity of outputs (the so-called "multitasking problem") and multiplicity of principals, of risk-aversion on the part of agents, of possible commitment issues, of dynamic relationships (the so-called "repeated game" models) and especially to introduce a third party, referred to as a supervisor, into three-tier hierarchy principal-agent models. In such a case, the possibility of collusion between the agent and the supervisor necessitates additional conditions to prevent the supervisor from colluding with the agent and further distorting economic activity. Overall, more elaborate principal-agent models usually call for caution in using performance incentives which may be very costly and must trade-off potential benefits with risks and distortions and be complemented by appropriate sanctions (Laffont and Martimort, 2002; Paul and Robinson, 2007; Baker, 2002).

In any case, the principal-agent literature has limited capacity to understand real-life assumptions reflecting the complexity of the health outcomes (especially those which are little dependent on agents' efforts), the difficulty and cost of correctly measuring performance and the need to compensate risk-adverse agents for uncertainty in terms of their remuneration (Paul and Robinson, 2007). It also disregards context influence, (for instance, principal-agent models assume there are two "types" of agents with varying productivity or efficiency, independent of the context), complexity of interactions between the various incentives resulting from ancillary components of $\mathrm{PBF}$ beyond financial premiums and implementation issues. Therefore, there is growing consensus that the principal-agent theory is not appropriate in order to support PBF (Barnes et al., 2015; Bigirimana et al., 2017; Paul and Renmans, 2018).

In conclusion, when used with realistic assumptions characterizing the context of the health sector in LMICs - that is, multi-principal and multitasking problems (Renmans et al., 2016b; Holmstrom and Milgrom, 1991; Conrad, 2015), high cost of verification of outputs (Borghi et al., 2015; Antony et al., 2017), possible collusion of supervisors (Turcotte-Tremblay et al., 2017), uncertainty of the link between agents' efforts and outputs (Bonfrer et al., 2014; Basinga et al., 2011; Rajkotia et al., 2017) - trade-offs must be made between the benefits, in terms of motivation, of "high-powered" incentives (that is, conditioning workers' remuneration to a large extent on outputs) and all the associated distortions and other 
costs (Baker, 2002). Thus, the principal-agent theory could actually warn against the use of too "high-powered" incentives (Baker, 2002).

It should be noted that many economic theories referred to in this review suffer from a lack of empirical validation-including the principal-agent theory, in the sense that contracts are rarely designed as predicted by theoretical models (Meessen, 2009; Prendergast, 1999), as well as the contractual approach inherent to PBF (Mills et al., 2001). The lack of empirical endorsement of theories is even more evident in the case of LMICs (Henrich et al., 2010), and recent advances in the health economics' literature emphasized the inappropriateness of the assumptions of the homo economicus and tried to develop more realistic descriptions of economic agents that are subject to emotions and psycho-social contexts (Emanuel et al., 2016; Loewenstein et al., 2012).

\section{Complexity of $P B F$}

The literature on PBF and related approaches are fragmented not only across different schools in economics, but also across disciplines; overall, much of the current crossdisciplinary research on PBF and similar schemes lacks a sound theoretical basis (Selviaridis and Wynstra, 2015). The multiplicity of the lenses under which PBF has been examined complicates the understanding of how it is supposed to work (or not). This complication might stem from the complexity of the PBF intervention. Indeed, PBF schemes comprise a package of elements-whose specific design may infinitely vary, hence our choice not to include individual program theories of change in this review-aimed at motivating healthcare providers at individual and organizational levels, but also at fostering system-wide reforms. An examination of the literature and $\mathrm{PBF}$ schemes allowed us to identify the following elements commonly included in PBF (Table 3 ).

It is probable that no single theory is sufficient to explain the complexity of PBF functioning - except perhaps complex adaptive systems (Turner and Baker, 2019). For instance, even when restricting itself to neo-institutional economic theories, the thesis of Meessen concluded that the various theories it resorted to were not redundant, but

Financial premiums...

$\ldots$ and therefore additional resources at facility level enabling to motivate health staff and/or to lead quality improvement activities and/or strengthening the local health system or health facility (hiring staff, buying equipment, etc.)

The conditioning of these premiums on reaching pre-agreed results

Independent verification of these results - sometimes coupled with counter-verification at community level, therefore enabling to enhance community voice and strengthen accountability

Feedback to healthcare providers on their performance compared to others', hence fostering a competitive spirit

Coaching and support to improve results by local and international experts - notably through results-based planning

Increased autonomy at facility level (yet, not all PBF schemes implement this principle)

... all of which is defined in a contract that also enables to separate functions and clarify roles and objectives and which is encrusted in a wider governance and regulation setting

Information systems strengthening

And often, various extra health system strengthening activities (e.g. training, hiring of contractual qualified

Table 3. healthcare providers, rehabilitation of facilities, etc.)

Common elements of a Source(s): Compilation by authors based on a review of literature (Fritsche et al., 2014; Renmans et al., 2016a, PBF program 2017b; Paul and Renmans, 2018, Sinahealth, 2017) and field experience 
complementary to each other, because they adopted different levels of analysis (Meessen, 2009). That complexity is also probably the reason why the "theory of change" associated with PBF is still misunderstood (Borghi et al., 2018). As a result, Renmans et al. acknowledged that "... if a multitude of elements influences the behaviour of the health workers and the organization of the facility, then a more complex view of human psychology and the management of health service delivery is warranted. Concepts and theories from disciplines such as economics (e.g. behavioural economics), psychology (e.g. cognitive evaluation theory), sociology (e.g. social learning), public health (e.g. patientcentred care), management sciences (e.g. new public management), educational sciences (e.g. transformative learning), political science [...] will have to be brought into the [Theory of Change]" (Renmans et al., 2017b). In other words, the justification for PBF can probably not be limited to the use of a single theory, all the more so since this review showed that many theories - especially economic ones - appeared to be poorly understood by some of the authors who referred to them.

\section{Further insights from the literature on high-income countries}

For a number of reasons explained in the introduction, this scoping review was limited to searching for justifications of PBF in LMICs. Nevertheless, additional theoretical insights that could help understand why PBF could be a preferred approach may be found in the literature on pay-for-performance in the context of high-income countries. Particularly, Trisolini (2011) "examines theoretical perspectives from economics, sociology, psychology, and organization theory to broaden our understanding of the range of factors affecting health care quality and cost outcomes and better understand why the focus of $\mathrm{P} 4 \mathrm{P}$ on economic incentives has had limited impact" (Trisolini, 2011). That chapter may be very helpful to better understand the specificities and connections of the various theories referred to and further demonstrate the abundance of theories that can possibly mobilized to justify, or at least explain, PBF. Another approach has been adopted by Conrad (2015), who applied lessons from agency theory and behavioral economics to examine how to achieve improved value - that is, better patient experience, clinical quality, health outcomes and lower costs of care - through appropriate incentives within provider payment arrangements. He explained how differing forms of value-based payment, coupled with adjunct incentives for quality and efficiency, could be tailored to different market conditions and organizational settings (Conrad, 2015).

\section{What can explain the enthusiasm for PBF?}

One might wonder why PBF has been fancied by many donors and stakeholders in the absence of a consistent and credible theory to support it. A number of early advocates for PBF (Eichler, 2006; Eichler et al., 2009; Preker et al., 2007; Meessen, 2009) advanced the principalagent theory to justify it. Perhaps this has prompted what psychologists call "theory-induced blindness: once you have accepted a theory and used it as a tool in your thinking, it is extraordinarily difficult to notice its flaws" (Kahneman, 2011) (p. 277). Moreover, "[t]heoretical beliefs are robust, and it takes much more than one embarrassing findings for established theories to be seriously questioned" (Kahneman, 2011) (p. 356).

\section{Limitations of this scoping study}

This study was confronted by the difficulty of defining what is a "grand" or a "mid-range" theory, compared to what is referred to as an intervention theory, or a theory of change; and in delineating what are the theories that underpin PBF compared to those that have been used to study, for instance, the diffusion of PBF (Gautier et al., 2019a, b), or the fidelity of its implementation (Bodson et al., 2018). If differences exist (in theory) between grand and mid-
Theories of PBF in LMICs 
range theories, the distinction between the two is uneasy in practice, and our analysis of included articles noted that the authors did not make it explicit, so we chose to group them together. Moreover, this study did not search for individual PBF scheme documentation and did not analyze the conceptual frameworks that were not backed by one or more grand or mid-range theories. Another difficulty lay in the relatively small number of useable studies identified as a result of a database search of the literature, calling for a manual addition of an important number of studies. This might have led to an incomplete record of the studies included in our review. Finally, the analysis was complicated by the fact that, as noted, many studies included in this review just alluded to one or several theories, without explaining how they really helped to support PBF. Our analysis might have been biased by having to extrapolate authors' understanding of these theories. Finally, we have focused the analytical part of this study on the principal-agent theory, which is by far the theory most referred to justify PBF; however, we have not looked in depth at the relevance of all the theories (especially, the psycho-social ones) utilized to study PBF, which could be the purpose of articles in future.

\section{Conclusion}

Our review showed that a multitude of economic and non-economic theories have been advanced to support PBF in LMICs. Perhaps because of the wide scope of our literature review, many studies included in this review limited themselves to alluding superficially to one or more theories, and very few used them to explain or support PBF. However, after conducting a critical analysis of the studies that were aimed at justifying PBF, we concluded that the theoretical justifications of PBF as a preferred approach remained unclear and insufficiently supported by convincing argumentation and consistent theoretical grounds. The profusion of theories supporting PBF is not a bad thing per se, but what is of concern is the fact that they seem to be invoked indiscriminately, seemingly without having been refined or logically articulated following accumulation of experience. Moreover, except for the principal-agent theory - which was often inappropriately applied and might warn against adopting PBF in such contexts as the health sector in LMICs - none has emerged as a dominant, consistent and credible theory. Overall, some 20 years after the implementation of PBF in LMICs, this review has not been able to identify a comprehensive, realistic, applicable, consistent theoretical justification for using PBF rather than alternative approaches to health system reforms and healthcare providers' motivation in LMICs. This review will perhaps encourage more debate and further exploration of the links between the theory and practice of $\mathrm{PBF}$ in order to probe more deeply into its appropriateness and efficacy in LMICs.

\section{Note}

1. The authors refer to Rosenthal (2007) to justify this assertion: Rosenthal, M. B. 2007. P4P: rumors of its demise may be exaggerated. Am J Manag Care, 13, 238-9.

\section{References}

Alonge, O., Lin, S., Igusa, T. and Peters, D.H. (2017), "Improving health systems performance in lowand middle-income countries: a system dynamics model of the pay-for-performance initiative in Afghanistan”, Health Policy and Planning, Vol. 32, pp. 1417-1426.

Aninanya, G.A., Howard, N., Williams, J.E., Apam, B., Prytherch, H., Loukanova, S., Kamara, E.K. and Otupiri, E. (2016), "Can performance-based incentives improve motivation of nurses and midwives in primary facilities in northern Ghana? A quasi-experimental study", Global Health Action, Vol. 9, p. 32404. 
Anselmi, L., Borghi, J., Brown, G.W., Fichera, E., Hanson, K., Kadungure, A., Kovacs, R., Kristensen, S.R., Singh, N.S. and Sutton, M. (2020), "Pay for performance: a reflection on how a global perspective could enhance policy and research", International Journal of Health Policy and Management.

Antony, M., Bertone, M.P. and Barthes, O. (2017), "Exploring implementation practices in resultsbased financing: the case of the verification in Benin", BMC Health Services Research, Vol. 17, p. 204, available at: https://www.ncbi.nlm.nih.gov/pmc/articles/PMC5348780/).

Arksey, H. and O'malley, L. (2005), "Scoping studies: towards a methodological framework", International Journal of Social Research Methodology, Vol. 8, pp. 19-32.

Baker, G. (2002), "Distortion and risk in optimal incentive contracts", Journal of Human Resources, Vol. 37, pp. 728-751.

Barnes, A., Brown, G.W. and Harman, S. (2015), Global Politics of Health Reform in Africa, Palgrave Macmillan, Basingstoke.

Basinga, P., Gertler, P.J., Binagwaho, A., Soucat, A.L., Sturdy, J. and Vermeersch, C.M. (2011), "Effect on maternal and child health services in Rwanda of payment to primary health-care providers for performance: an impact evaluation", Lancet, Vol. 377, pp. 1421-1428.

Béland, D. and Cox, R.H. (2011), Ideas and Politics in Social Science Research, Oxford University Press, New York, NY, NJ.

Bhatnagar, A. and George, A.S. (2016), "Motivating health workers up to a limit: partial effects of performance-based financing on working environments in Nigeria", Health Policy and Planning, Vol. 31, pp. 868-877.

Bigirimana, E., Eerens, P., Eichler, R., Meessen, B. and Quigley, P. (2017), "Some reflections on PBF theory of change and quality of care", in Group, T.W. (Ed.), Improving Quality of Care Measurement of Family Planning in Performance-Based Financing System, September 14 2017, Antwerp.

Binyaruka, P., Patouillard, E., Powell-Jackson, T., Greco, G., Maestad, O. and Borghi, J. (2015), "Effect of paying for performance on utilisation, quality, and user costs of health services in Tanzania: a controlled before and after study", PloS One, Vol. 10, e0135013.

Birken, S.A., Powell, B.J., Shea, C.M., Haines, E.R., Alexis Kirk, M., Leeman, J., Rohweder, C., Damschroder, L. and Presseau, J. (2017), "Criteria for selecting implementation science theories and frameworks: results from an international survey”, Implementation Science, Vol. 12, p. 124.

Bodson, O., Barro, A., Turcotte-Tremblay, A.M., Zante, N., Some, P.A. and Ridde, V. (2018), "A study on the implementation fidelity of the performance-based financing policy in Burkina Faso after 12 months", Arch Public Health, Vol. 76, p. 4.

Bonfrer, I., Van De Poel, E. and Van Doorslaer, E. (2014), "The effects of performance incentives on the utilization and quality of maternal and child care in Burundi”, Social Science and Medicine, Vol. 123, pp. 96-104.

Borghi, J., Little, R., Binyaruka, P., Patouillard, E. and Kuwawenaruwa, A. (2015), "In Tanzania, the many costs of pay-for-performance leave open to debate whether the strategy is cost-effective", Health Affairs, Vol. 34, pp. 406-414.

Borghi, J., Singh, N.S., Brown, G., Anselmi, L. and Kristensen, S. (2018), "Understanding for whom, why and in what circumstances payment for performance works in low and middle income countries: protocol for a realist review", BMJ Global Health, Vol. 3 No. 3, e000695, (see https:// pubmed.ncbi.nlm.nih.gov/29988988/).

Breton, E. and De Leeuw, E. (2011), "Theories of the policy process in health promotion research: a review", Health Promotion International, Vol. 26, pp. 82-90.

Brown, G.W., Barnes, A., Harman, S., Gruia, M. and Papamichail, A. (2013), "Annotated literature review: African actors, global health governance and performance-based funding”. EQUINET Discussion Paper, EQUINET, Harare. 
Chimhutu, V., Lindkvist, I. and Lange, S. (2014), "When incentives work too well: locally implemented pay for performance (P4P) and adverse sanctions towards home birth in Tanzania - a qualitative study", BMC Health Services Research, Vol. 14, p. 23.

Chimhutu, V., Songstad, N.G., Tjomsland, M., Mrisho, M. and MOLAND, K.M. (2016), "The inescapable question of fairness in Pay-for-performance bonus distribution: a qualitative study of health workers' experiences in Tanzania", Global Health, Vol. 12, p. 77.

Conrad, D.A. (2015), "The theory of value-based payment incentives and their application to health care”, Health Services Research, Vol. 50 Suppl 2, pp. 2057-2089.

Dardot, P. and Laval, C. (2010), "La nouvelle raison du monde - essai sur la société néolibérale", La Découverte Poche, No. 325, p. 504, ISBN : 9782707165022.

Das, A., Gopalan, S.S. and Chandramohan, D. (2016), "Effect of pay for performance to improve quality of maternal and child care in low- and middle-income countries: a systematic review", BMC Public Health, Vol. 16, p. 321.

Daudt, H.M.L., Van Mossel, C. and Scott, S.J. (2013), "Enhancing the scoping study methodology: a large, inter-professional team's experience with Arksey and O'Malley's framework", BMC Medical Research Methodology, Vol. 13, p. 48.

De Allegri, M., Bertone, M.P., Mcmahon, S., Mounpe Chare, I. and Robyn, P.J. (2018), "Unraveling PBF effects beyond impact evaluation: results from a qualitative study in Cameroon", BMJ Glob Health, Vol. 3, e000693.

De Walque, D., Robyn, P.J., Saidou, H., Sorgho, G. and Steenland, M. (2017). "Looking into the performance-based financing black box: evidence from an impact evaluation in the health sector in Cameroon”. Policy Research Working Paper, The World Bank, Washington, DC.

Degroote, S., Zinszer, K. and Ridde, V. (2018), "Interventions for vector-borne diseases focused on housing and hygiene in urban areas: a scoping review", Infectious Diseases of Poverty, Vol. 7, p. 96.

Eichler, R. (2006), "Can Pay for performance, increase utilization by the poor and improve the quality of health services", Background Papers for the Working Group on Performance Based Incentives, Center for Global Development, Washington, DC.

Eichler, R., Auxila, P. and Pollock, J. (2001), Output-Based Health Care: Paying for Performance in Haiti. Viewpoint, The World Bank, Washington, DC.

Eichler, R. and levine, R. and Group, A. T. P.-B. I. W. (2009), Performance Incentives for Global Health. Potential and Pitfalls, Center for Global Development, Washington, DC.

Eijkenaar, F., Emmert, M., Scheppach, M. and Schöffski, O. (2013), "Effects of pay for performance in health care: a systematic review of systematic reviews", Health Policy, Vol. 110, pp. 115-130.

Eldridge, C. and Palmer, N. (2009), "Performance-based payment: some reflections on the discourse, evidence and unanswered questions", Health Policy Plan, Vol. 24, pp. 160-166.

Emanuel, E.J., Ubel, P.A., Kessler, J.B., Meyer, G., Muller, R.W., Navathe, A.S., Patel, P., Pearl, R., Rosenthal, M.B., Sacks, L., Sen, A.P., Sherman, P. and Volpp, K.G. (2016), "Using behavioral economics to design physician incentives that deliver high-value care", Annals of Internal Medicine, Vol. 164, pp. 114-119.

Engineer, C.Y., Dale, E., Agarwal, A., Agarwal, A., alonge, O., Edward, A., Gupta, S., Schuh, H.B., Burnham, G. and peters, D.H. (2016), "Effectiveness of a pay-for-performance intervention to improve maternal and child health services in Afghanistan: a cluster-randomized trial", International Journal of Epidemiology, Vol. 45, pp. 451-459.

Fritsche, G.B., Soeters, R. and Meessen, B. (2014), Performance-Based Financing Toolkit, The World Bank, Washington, DC.

Gautier, L., Tosun, J., De Allegri, M. and Ridde, V. (2018), "How do diffusion entrepreneurs spread policies? Insights from performance-based financing in Sub-Saharan Africa”, World Development, Vol. 110, pp. 160-175. 
Gautier, L., Coulibaly, A., De Allegri, M. and Ridde, V. (2019a), "From Amsterdam to Bamako: a qualitative case study on diffusion entrepreneurs' contribution to performance-based financing propagation in Mali”, Health Policy Plan, Vol. 34 No. 9, pp. 656-666, available at: https:// academic.oup.com/heapol/article-abstract/34/9/656/5570539.

Gautier, L., De Allegri, M. and Ridde, V. (2019b), "How is the discourse of performance-based financing shaped at the global level? A poststructural analysis", Global Health, Vol. 15, p. 6.

Gram, L., Fitchett, A., Ashraf, A., Daruwalla, N. and Osrin, D. (2019), "Promoting women's and children's health through community groups in low-income and middle-income countries: a mixed-methods systematic review of mechanisms, enablers and barriers", BMJ Global Health, Vol. 4, e001972.

Hasnain, Z., Manning, N. and Pierskalla, J.H. (2014), "The promise of performance pay? Reasons for caution in policy prescriptions in the core civil service", The World Bank Research Observer, Vol. 29, pp. 235-264.

Helland, J. and Maestad, O. (2015), Basis for Decisions to Use Results-Based Payments in Norwegian Development Aid, Norwegian Agency for Development Cooperation, Norad, Bergen.

Henrich, J., Heine, S.J. and Norenzayan, A. (2010), "Most people are not WEIRD”, Nature, Vol. 466, p. 29.

Henrion, E., Struwig, A., Wedgwood Young, E., Guay, M. and Duering, C. (2018), Health Results Innovation Trust Fund Mid Term Review - Final Report, International Organisation Development (IOD PARC), Sheffield.

Holmstrom, B. and Milgrom, P. (1991), "Multitask principal-agent analyses: incentive contracts, asset ownership, and job design”, Journal of Law, Economics, and Organization, Vol. 7, pp. 24-52.

Imenda, S. (2014), "Is there a conceptual difference between theoretical and conceptual frameworks?", Journal of Social Sciences, Vol. 38, pp. 185-195.

Ireland, M., Paul, E. and Dujardin, B. (2011), "Can performance-based financing be used to reform health systems in developing countries?", Bulletin of the World Health Organization, Vol. 89, pp. 695-698.

Jaccard, J. and Jacoby, J. (2009), Theory Construction And Model-Building Skills. A Practical Guide for Social Scientists, Guilford Press, New York, NY.

Jahn, A., Paul, F. and Beiersmann, C. (2013), Peer Review: Results-Based Financing of Maternal and Newborn Health Care in Low and Lower-Middle Income Countries, Evaplan at the University Hospital Heidelberg, Heidelberg.

Kahneman, D. (2011), Thinking, Fast and Slow, Penguin Books.

Kalk, A. (2011), "The costs of performance-based financing", Bulletin of the World Health Organization, Vol. 89, p. 319.

Kalk, A., Paul, F.A. and Grabosch, E. (2010), "Paying for performance' in Rwanda: does it pay off?", Tropical Medicine and International Health, Vol. 15, pp. 182-190.

Kandpal, E. (2017), Completed Impact Evaluations and Emerging Lessons from the Health Results Innovation Trust Fund Learning Portfolio, The World Bank, Washington, DC.

Khim, K. (2016), "Are health workers motivated by income? Job motivation of Cambodian primary health workers implementing performance-based financing", Global Health Action, Vol. 9, p. 31068.

Kislov, R., Pope, C., Martin, G.P. and Wilson, P.M. (2019), "Harnessing the power of theorising in implementation science", Implementation Science, Vol. 14, p. 103.

Kolstad, J.R. and Lindkvist, I. (2013), "Pro-social preferences and self-selection into the public health sector: evidence from an economic experiment", Health Policy and Planning, Vol. 28, pp. 320-327.

Kovacs, R.J., Powell-Jackson, T., Kristensen, S.R., Singh, N. and Borghi, J. (2020), "How are pay-forperformance schemes in healthcare designed in low- and middle-income countries? Typology and systematic literature review", BMC Health Services Research, Vol. 20, p. 291. 
Laffont, J.-J. and Martimort, D. (2002), "The theory of incentives", The Principal-Agent Model, Princeton University Press, Princeton, NJ.

Lannes, L. (2015), "Improving health worker performance: the patient-perspective from a PBF program in Rwanda", Social Science and Medicine, Vol. 138, pp. 1-11.

Lannes, L., Meessen, B., Soucat, A. and Basinga, P. (2016), "Can performance-based financing help reaching the poor with maternal and child health services? The experience of rural Rwanda", The International Journal of Health Planning and Management, Vol. 31, pp. 309-348.

Lawson, T. (1997), Economics and Reality, Routledge, London, New York.

Lee, K. and Goodman, H. (2002), "Global policy networks : the propagation of health care financing reform since the 1980s", in Lee, K., Buse, K. and Fustukian, S. (Eds), Health Policy in a Globalising World, Cambridge University Press, Cambridge.

Levac, D., Colquhoun, H. and O'brien, K.K. (2010), "Scoping studies: advancing the methodology", Implementation Science, Vol. 5, p. 69.

Lindkvist, I. and Bastøe, P.Ø. (2015), "Results-based financing has potential but is not a silver bullet theory-based evaluations and research can improve the evidence base for decision making", Discussion Paper // Report 4\&5, Evaluation Department, Norwegian Agency for Development Cooperation (Norad), Bergen.

Lipsey, M.W. (1993), "Theory as method: small theories of treatments", New Directions for Program Evaluation, Vol. 1993, pp. 5-38.

Loewenstein, G., Volpp, K.G. and Asch, D.A. (2012), "Incentives in health: different prescriptions for physicians and patients", Journal of the American Medical Association, Vol. 307, pp. 1375-1376.

Lohmann, J., Houlfort, N. and De Allegri, M. (2016), "Crowding out or no crowding out? A SelfDetermination Theory approach to health worker motivation in performance-based financing", Social Science and Medicine, Vol. 169, pp. 1-8.

Lohmann, J., Muula, A.S., Houlfort, N. and De Allegri, M. (2018a), "How does performance-based financing affect health workers' intrinsic motivation? A self-determination theory-based mixedmethods study in Malawi”, Social Science and Medicine, Vol. 208, pp. 1-8.

Lohmann, J., Wilhelm, D., Kambala, C., Brenner, S., Muula, A.S. and De Allegri, M. (2018b), "The money can be a motivator, to me a little, but mostly PBF just helps me to do better in my job.' an exploration of the motivational mechanisms of performance-based financing for health workers in Malawi”, Health Policy Plan, Vol. 33, pp. 183-191.

Mabuchi, S., Sesan, T. and Bennett, S.C. (2018), "Pathways to high and low performance: factors differentiating primary care facilities under performance-based financing in Nigeria”, Health Policy Plan, Vol. 33, pp. 41-58.

Magrath, P. and Nichter, M. (2012), "Paying for performance and the social relations of health care provision: an anthropological perspective”, Social Science and Medicine, Vol. 75, pp. 1778-1785.

Manitu, S.M., Meessen, B., Lushimba, M.M. and Macq, J. (2015), "[The debate concerning performancebased financing in Africa South of the Sahara: analysis of the nature]", Sante Publique, Vol. 27, pp. 117-128.

Manongi, R., Mushi, D., Kessy, J., Salome, S. and Njau, B. (2014), "Does training on performance based financing make a difference in performance and quality of health care delivery? Health care provider's perspective in Rungwe Tanzania”, BMC Health Services Research, Vol. 14, p. 154.

Maynard, A. (2012), "The powers and pitfalls of payment for performance", Health Economics, Vol. 21, pp. 3-12.

Mcmahon, S.A., Brenner, S., Lohmann, J., Makwero, C., Torbica, A., Mathanga, D.P., Muula, A.S. and De Allegri, M. (2016), "Evaluating complex health financing interventions: using mixed methods to inform further implementation of a novel PBI intervention in rural Malawi”, $B M C$ Health Services Research, Vol. 16, p. 414, available at: https://bmchealthservres.biomedcentral. com/articles/10.1186/s12913-016-1612-2\#citeas. 
Mcmahon, S.A., Muula, A.S. and De Allegri, M. (2018), “I wanted a skeleton they brought a prince': a qualitative investigation of factors mediating the implementation of a Performance Based Incentive program in Malawi", SSM - Population Health, Vol. 5, pp. 64-72.

Meessen, B. (2009), An Institutional Economic Analysis of Public Health Care Organisations in LowIncome Countries, $\mathrm{PhD}$, Université Catholique de Louvain.

Meessen, B., Soucat, A. and Sekabaraga, C. (2011), "Performance-based financing: just a donor fad or a catalyst towards comprehensive health-care reform?", Bulletin of the World Health Organization, Vol. 89, pp. 153-156.

Mills, A., Bennett, S., Russell, S., Attanayake, N., Hongoro, C., Muraleedharan, V.R. and Smithson, P. (2001), The Challenge of Health Sector Reform - what Must Governments Do??, Palgrave Macmillan, London.

Munar, W., Wahid, S.S. and Curry, L. (2018), "Characterizing performance improvement in primary care systems in Mesoamerica: a realist evaluation protocol", Gates Open Research, Vol. 2, p. 1.

Nimpagaritse, M., Korachais, C., Roberfroid, D., Kolsteren, P., Zine Eddine El Idrissi, M.D. and Meessen, B. (2016), "Measuring and understanding the effects of a performance based financing scheme applied to nutrition services in Burundi-a mixed method impact evaluation design", International Journal for Equity in Health, Vol. 15, p. 93.

Ogundeji, Y.K. (2015), Pay-For-Performance for Health Service Providers - Effectiveness, Design, Context, and Implementation, Doctor of Philosophy, University of York.

Ogundeji, Y.K., Jackson, C., Sheldon, T., Olubajo, O. and Ihebuzor, N. (2016), "Pay for performance in Nigeria: the influence of context and implementation on results", Health Policy and Planning, Vol. 31, pp. 955-963.

Ogundeji, Y.K., Sheldon, T.A. and Maynard, A. (2018), "A reporting framework for describing and a typology for categorizing and analyzing the designs of health care pay for performance schemes", BMC Health Services Research, Vol. 18, p. 686, available at: https://bmchealthservres. biomedcentral.com/articles/10.1186/s12913-018-3479-x.

Patton, M.Q. (2002), Qualitative Research and Evaluation Methods, Sage Publications, Thousand Oaks, London, New Delhi.

Paul, E. (2006), "Lessons from principal-agent theory for public expenditure management in Pacific island countries", Pacific Economic Bulletin, Vol. 21, pp. 36-52.

Paul, E. and Renmans, D. (2018), "Performance-based financing in the heath sector in low- and middleincome countries: is there anything whereof it may be said, see, this is new?", International Journal of Health Planning and Management, Vol. 33, pp. 51-66.

Paul, E. and Ridde, V. (2018), "Oser remettre en question un modèle voyageur? Le cas du financement basé sur les résultats (FBR) en Afrique”, in Oral Communication, Cinquiémes Rencontres des Études Africaines en France, Marseille, 9-12 July 2018.

Paul, E. and Robinson, M. (2007), "Performance budgeting, motivation and incentives", in Robinson, M. (Ed.), Performance Budgeting: Linking Funding and Results, International Monetary Fund \& Palgrave/McMillan.

Paul, E., Sossouhounto, N. and Eclou, D.S. (2014), "Local stakeholders' perceptions about the introduction of performance-based financing in Benin: a case study in two health districts", International Journal of Health Policy and Management, Vol. 3, pp. 207-214.

Paul, E., Albert, L., Bisala, B.N., Bodson, O., Bonnet, E., Bossyns, P., Colombo, S., De Brouwere, V., Dumont, A., Eclou, D.S., Gyselinck, K., Hane, F., Marchal, B., Meloni, R., Noirhomme, M., Noterman, J.P., Ooms, G., Samb, O.M., Ssengooba, F., Toure, L., Turcotte-Tremblay, A.M., Van Belle, S., Vinard, P. and Ridde, V. (2018a), "Performance-based financing in low-income and middle-income countries: isn't it time for a rethink?", BMJ Global Health, Vol. 3, e000664.

Paul, E., Dramé, M.L., Kashala, J.P., Ndema, A.E., Kounnou, M., Ä̈ssan, J.C. and Gyselinck, K. (2018b), "Performance-based financing to strengthen the health system in Benin: challenging the 
mainstream approach", International Journal of Health Policy and Management, Vol. 7, pp. 35-47.

Preker, A.S., Liu, X., Velenyi, E.V. and Baris, E. (Eds) (2007), "Public ends, private means : strategic purchasing of health services", World Bank, Washington, DC.

Prendergast, C. (1999), "The provision of incentives in firms", Journal of Economic Literature, Vol. 37, pp. 7-63.

Rajkotia, Y., Zang, O., Nguimkeu, P., Gergen, J., Djurovic, I., Vaz, P., Mbofana, F. and Jobarteh, K. (2017), "The effect of a performance-based financing program on HIV and maternal/child health services in Mozambique-an impact evaluation", Health Policy and Planning, Vol. 32, pp. 1386-1396.

Renmans, D., Holvoet, N., Orach, C.G. and Criel, B. (2016a), "Opening the 'black box' of performancebased financing in low- and lower middle-income countries: a review of the literature", Health Policy Plan, Vol. 31, pp. 1297-1309.

Renmans, D., Paul, E. and Dujardin, B. (2016b), Analysing Performance-Based Financing through the Lenses of the Principal-Agent Theory, Institute of Development Policy and Management, University of Antwerp, Antwerp.

Renmans, D., Holvoet, N. and Criel, B. (2017a), "Combining theory-driven evaluation and causal loop diagramming for opening the 'black box' of an intervention in the health sector: a case of performance-based financing in western Uganda", International Journal of Environmental Research and Public Health, Vol. 14, p. 1007.

Renmans, D., Holvoet, N., Criel, B. and Meessen, B. (2017b), "Performance-based financing: the same is different", Health Policy Plan, Vol. 32, pp. 860-868.

Ridde, V. (2005), "Building trust or buying results?”, Lancet, Vol. 366, p. 1692.

Ridde, V., Turcotte-Tremblay, A.M., Souares, A., Lohmann, J., Zombre, D., Koulidiati, J.L., Yaogo, M., Hien, H., Hunt, M., Zongo, S. and De Allegri, M. (2014), "Protocol for the process evaluation of interventions combining performance-based financing with health equity in Burkina Faso", Implementation Science, Vol. 9, p. 149.

Ridde, V., Gautier, L., Turcotte-Tremblay, A.M., Sieleunou, I. and Paul, E. (2018), "Performance-based financing in africa: time to test measures for equity", International Journal of Health Services, Vol. 48, pp. 549-561.

Ridde, V., Pérez, D. and Robert, E. (2020), "Using implementation science theories and frameworks in global health", BMJ Global Health, Vol. 5, e002269.

Rosenthal, M.B. (2007), "P4P: rumors of its demise may be exaggerated", American Journal of Managed Care, Vol. 13, pp. 238-239.

Saetren, H. (2014), "Implementing the third generation research paradigm in policy implementation research: an empirical assessment", Public Policy and Administration, Vol. 29, pp. 84-105.

Scheffler, R. (2010), "Pay for performance (P4P) programs in health services: what is the evidence?", World Health Report (2010) Background Paper, World Health Organization, Geneva.

Schuster, R.C., De Sousa, O., Rivera, J., Olson, R., Pinault, D. and Young, S.L. (2016), "Performancebased incentives may be appropriate to address challenges to delivery of prevention of vertical transmission of HIV services in rural Mozambique: a qualitative investigation”, Human Resources for Health, Vol. 14, p. 60.

Schuster, R.C., De Sousa, O., Reme, A.K., Vopelak, C., Pelletier, D.L., Johnson, L.M., Mbuya, M., Pinault, D. and Young, S.L. (2018), "Performance-based financing empowers health workers delivering prevention of vertical transmission of HIV services and decreases desire to leave in Mozambique", International Journal of Health Policy and Management, Vol. 7, pp. 630-644.

Scott, S.D., Rotter, T., Flynn, R., Brooks, H.M., Plesuk, T., Bannar-Martin, K.H., Chambers, T. and Hartling, L. (2019), "Systematic review of the use of process evaluations in knowledge translation research", Systematic Reviews, Vol. 8, p. 266. 
Selviaridis, K. and Wynstra, F. (2015), "Performance-based contracting: a literature review and future research directions", International Journal of Production Research, Vol. 53, pp. 3505-3540.

Shen, G.C., Nguyen, H.T., Das, A., Sachingongu, N., Chansa, C., Qamruddin, J. and Friedman, J. (2017), "Incentives to change: effects of performance-based financing on health workers in Zambia", Human Resources for Health, Vol. 15, p. 20.

Sinahealth (2017), Performance-based Financing in Action -Theory and Instruments - Course Guide with 17 Modules, SinaHealth, Den Haag.

Skiles, M.P., Curtis, S.L., Basinga, P., Angeles, G. and Thirumurthy, H. (2015), "The effect of performance-based financing on illness, care-seeking and treatment among children: an impact evaluation in Rwanda", BMC Health Services Research, Vol. 15, p. 375.

Spisak, C., Morgan, L., Eichler, R., Rosen, J., Serumaga, B. and wang, A. (2016), "Results-based financing in Mozambique's central medical store: a review after 1 year", Global Health Science and Practice, Vol. 4, pp. 165-177.

Ssengooba, F., Mcpake, B. and Palmer, N. (2012), "Why performance-based contracting failed in Uganda - an 'open-box' evaluation of a complex health system intervention”, Social Science and Medicine, Vol. 75, pp. 377-383.

Suthar, A.B., Nagata, J.M., Nsanzimana, S., Barnighausen, T., Negussie, E.K. and Doherty, M.C. (2017), "Performance-based financing for improving HIV/AIDS service delivery: a systematic review", BMC Health Services Research, Vol. 17, p. 6.

Tricco, A.C., Lillie, E., Zarin, W., O’brien, K.K., Colquhoun, H., Levac, D., Moher, D., Peters, M.D.J., Horsley, T., Weeks, L., Hempel, S., Akl, E.A., Chang, C., Mcgowan, J., Stewart, L., Hartling, L., Aldcroft, A., Wilson, M.G., Garritty, C., Lewin, S., Godfrey, C.M., Macdonald, M.T., Langlois, E.V., Soares-Weiser, K., Moriarty, J., Clifford, T., Tuncalp, O. and Straus, S.E. (2018), "PRISMA extension for scoping reviews (PRISMA-ScR): checklist and explanation", Annals of Internal Medicine, Vol. 169, pp. 467-473.

Trisolini, M.G. (2011), "Theoretical perspectives on pay for performance", in Cromwell, J.T.M., Pope, G.C., Mitchell, J.B. and Greenwald, L.M. (Eds), Pay for Performance in Health Care: Methods and Approaches. Research Triangle Institute, RTI Press publication, Research Triangle Park, NC.

Turcotte-Tremblay, A.M., Spagnolo, J., De Allegri, M. and Ridde, V. (2016), "Does performance-based financing increase value for money in low- and middle- income countries? A systematic review", Health Economic Review, Vol. 6, p. 30.

Turcotte-Tremblay, A.M., Gali-Gali, I.A., De Allegri, M. and Ridde, V. (2017), "The unintended consequences of community verifications for performance-based financing in Burkina Faso", Social Science and Medicine, Vol. 191, pp. 226-236.

Turcotte-Tremblay, A.-M., Gali Gali, I.A. and Ridde, V. (2020), "An exploration of the unintended consequences of performance-based financing in 6 primary healthcare facilities in Burkina Faso", International Journal of Health Policy and Management, Epub ahead of print, PMID: 32610814, available at: https://pubmed.ncbi.nlm.nih.gov/32610814/, doi: 10.34172/ijhpm.2020.83.

Turner, J.R. and Baker, R.M. (2019), "Complexity theory: an overview with potential applications for the social sciences", Systems, Vol. 7, p. 4.

Walt, G., Shiffman, J., Schneider, H., Murray, S.F., Brugha, R. and Gilson, L. (2008), "Doing' health policy analysis: methodological and conceptual reflections and challenges", Health Policy and Planning, Vol. 23, pp. 308-317.

Weiss, C.H. (1998), Evaluation: Methods for Studying Programs and Policies, Prenctice Hall, Upper Saddle River, NJ.

Zeng, W., Shepard, D.S., Nguyen, H., Chansa, C., Das, A.K., Qamruddin, J. and Friedman, J. (2018), "Cost-effectiveness of results-based financing, Zambia: a cluster randomized trial", Bulletin of the World Health Organization, Vol. 96, pp. 760-771.
Theories of PBF in LMICs 
Equation used in PubMed (23 July 2019):

((“'developing country”[title/abstract] OR “developing countries”[Mesh]OR “developing countries”[title/ abstract] OR "low income countries"[title/abstract] OR "low income country"[title/abstract] OR "lowincome countries"[title/abstract] OR "low-income country"[title/abstract] OR "middle-income countries"[title/abstract] OR "middle-income country"[title/abstract] OR "low and middle income country"[Title/Abstract] OR "low and middle income countries"[Title/Abstract] OR "low- and middle income country"[Title/Abstract] OR "low- and middle income countries"[Title/Abstract] OR LMIC[Title/ Abstract] OR LMICs[Title/Abstract] OR "Fragile and conflict affected"[Title/Abstract] OR ("cryopyrinassociated periodic syndromes"[MeSH Terms] OR ("cryopyrin-associated"[All Fields] AND "periodic"[All Fields] AND "syndromes"[All Fields]) OR “cryopyrin-associated periodic syndromes"[All Fields] OR "fcas"[All Fields]) OR Africa[Title/Abstract] OR Asia[Title/Abstract] OR "Latin America"[Title/Abstract] OR "Central America"[Title/Abstract] OR "Pacific Island Countries"[Title/Abstract] OR "Eastern Europe"[Title/Abstract] OR Afghanistan[Title/Abstract] OR Benin[Title/Abstract] OR "Burkina Faso"[Title/Abstract] OR Burundi[Title/Abstract] OR "Central African Republic"[Title/Abstract] OR Chad[Title/Abstract] OR Comoros[Title/Abstract] OR "Democratic Republic of Congo"[Title/Abstract] OR "Democratic Republic of the Congo"[Title/ Abstract] OR DRC[Title/Abstract] OR Eritrea[Title/Abstract] OR Ethiopia[Title/Abstract] OR Gambia[Title/Abstract] OR Guinea[Title/Abstract] OR Guinea-Bissau[Title/Abstract] OR Haiti[Title/ Abstract] OR "North Korea"[Title/Abstract] OR "Democratic People's Republic of Korea"[Title/ Abstract] OR Liberia[Title/Abstract] OR Madagascar[Title/Abstract] OR Malawi[Title/Abstract] OR Mali[Title/Abstract] OR Mozambique[Title/Abstract] OR Nepal[Title/Abstract] OR Niger[Title/ Abstract] OR Rwanda[Title/Abstract] OR Senegal[Title/Abstract] OR "Sierra Leone"[Title/Abstract] OR Somalia[Title/Abstract] OR "South Sudan"[Title/Abstract] OR Syria[Title/Abstract] OR "Syrian Arab Republic"[Title/Abstract] OR Tajikistan[Title/Abstract] OR Tanzania[Title/Abstract] OR Togo [Title/Abstract] OR Uganda[Title/Abstract] OR Yemen[Title/Abstract] OR Zimbabwe[Title/Abstract] OR Angola[Title/Abstract] OR Bangladesh[Title/Abstract] OR Bhutan[Title/Abstract] OR Bolivia[Title/ Abstract] OR "Cabo Verde"[Title/Abstract] OR Cambodia[Title/Abstract] OR Cameroon[Title/Abstract] OR "Republic of Congo"[Title/Abstract] OR "Republic of the Congo"[Title/Abstract] OR "Cote d'Ivoire"[Title/Abstract] OR "Ivory Coast"[Title/Abstract] OR Djibouti[Title/Abstract] OR Egypt [Title/Abstract] OR "ElSalvador"[Title/Abstract] OR Georgia[Title/Abstract] OR Ghana[Title/Abstract] OR Honduras[Title/Abstract] OR India[Title/Abstract] OR Indonesia[Title/Abstract] OR Kenya[Title/ Abstract] OR Kiribati[Title/Abstract] OR Kosovo[Title/Abstract] OR "Kyrgyz Republic"[Title/Abstract] OR Laos[Title/Abstract] OR "Lao PDR"[Title/Abstract] OR Lesotho[Title/Abstract] OR Mauritania [Title/Abstract] OR Micronesia[Title/Abstract] OR Moldova[Title/Abstract] OR Mongolia[Title/ Abstract] OR Morocco[Title/Abstract] OR Myanmar[Title/Abstract] OR Nicaragua[Title/Abstract] OR Nigeria[Title/Abstract] OR Pakistan[Title/Abstract] OR "Papua New Guinea"[Title/Abstract] OR Philippines[Title/Abstract] OR "Sao Tome and Principe"[Title/Abstract] OR "Solomon Islands"[Title/ Abstract] OR "Sri Lanka”[Title/Abstract] OR Sudan[Title/Abstract] OR Swaziland[Title/Abstract] OR Timor-Leste[Title/Abstract] OR Tunisia[Title/Abstract] OR Ukraine[Title/Abstract] OR Uzbekistan [Title/Abstract] OR Vanuatu[Title/Abstract] OR Vietnam[Title/Abstract] OR "West Bank and Gaza"[Title/Abstract] OR Zambia[Title/Abstract] OR Argentina[Title/Abstract] OR "Poverty"[Mesh]) AND (health[title/abstract] OR healthcare[title/abstract] OR sanitary[title/abstract] OR "Delivery of Health Care"[Mesh] OR "Health"[Mesh]) AND (theory[title/abstract] OR theories[title/abstract] OR theoretical[title/abstract] OR theoretically[title/abstract])) AND ("performance-based financing"[title/ abstract] OR PBF[title/abstract] OR "results-based financing"[title/abstract] OR RBF[title/abstract] OR "pay-for-performance"[title/abstract] OR "pay for performance"[title/abstract] OR P4P[title/abstract] OR "payment for performance"[title/abstract] OR "performance-based payment"[title/abstract] OR "performance-based contracting"[title/abstract] OR "monetary incentive"[title/abstract] OR "financial incentive"[title/abstract] OR "economic incentive"[title/abstract] OR "financial reward"[title/abstract] OR "economic reward"[title/abstract] OR "Reimbursement, Incentive"[Mesh] OR "performance-based payments"[title/abstract] OR "monetary incentives"[title/abstract] OR "financial incentives"[title/ abstract] OR "economic incentives"[title/abstract] OR "financial rewards"[title/abstract] OR "economic 
rewards"[title/abstract] OR "performance-based incentive"[title/abstract] OR "performance-based incentives"[title/abstract] OR PBI[title/abstract] OR PBC[title/abstract] OR "output-based aid"[title/ abstract] OR OBA[title/abstract] OR "cash on delivery"[title/abstract] OR COD[title/abstract] OR "conditional cash transfer"[title/abstract] OR "conditional cash transfers"[title/abstract] OR CCT[title/ abstract]) AND “loattrfull text”[sb]

\section{Equation used in Scopus (15 July 2019) and ProQuest* (23 July 2019):}

* Databases included:

(1) International Bibliography of the Social Sciences (IBSS)

(2) Within ProQuest central: Business Market Research Collection (1986 - current); Consumer Health Database; Continental Europe Database; East \& South Asia Database; East Europe, Central Europe Database; Health \& Medical Collection; Healthcare Administration Database; India Database; Latin America \& Iberia Database; Middle East \& Africa Database; Nursing \& Allied Health Database; Political Science Database; Public Health Database; Social Science Database; Sociology Database; UK \& Ireland Database

(3) Sociological Abstracts

( TITLE-ABS-KEY ( "performance-based financing” OR pbf OR "results-based financing” OR $r b f$ OR "pay-for-performance" OR "pay for performance" OR p4p OR "payment for performance" OR "performance-based payment" OR "performance-based contracting" OR "results-based contracting" $\mathrm{OR}$ "results-based payment" OR "monetary incentive" OR "financial incentive" OR "economic incentive" OR "financial reward" OR "economic reward" OR "performance-based payments" OR "monetary incentives" OR "financial incentives" OR "economic incentives" OR "financial rewards" OR "economic rewards" OR "performance-based incentive" OR "performance-based incentives" OR PBI OR PBC OR "financement base sur la performance" OR "FBP" OR "financement base sur les resultats" OR "FBR" OR "paiement a la performance" OR "prime de performance" OR "primes de performance" OR "prime financiere" OR "primes financieres" OR "incitant financier" OR "incitants financiers" OR "paiement a la performance" OR "paiement base sur la performance" OR "paiement base sur les resultats") AND TITLE-ABS-KEY ( theory OR theories OR theoretical OR theoretically OR theorie OR theorique ) AND TITLE-ABS-KEY ( health OR healthcare OR sanitary OR sante OR sanitaire )) AND TITLE-ABS-KEY ( "developing country" OR "developing countries" OR "low income countries" OR "low income country" $\mathrm{OR}$ "low-income countries" $\mathrm{OR}$ "low-income country" OR "middle-income countries" OR "middle-income country" OR "low and middle income country" OR "low and middle income countries" OR lmic OR lmics OR "pays a revenu faible et intermédiaire" OR "pays a revenus faibles et intermédiaires" OR prfi OR "pays a revenu faible et moyen" $\mathrm{OR}$ "pays a revenus faibles et moyens" $\mathrm{OR}$ "pays a faible ou moyen revenu" $\mathrm{OR}$ "pays a faibles et moyens revenus" OR prfm OR "pays a revenu faible" OR "pays a revenus faibles" OR "pays a revenu intermediaire" OR "pays a revenus intermediaires" OR "Fragile and conflict affected country" OR "Fragile and conflict affected states" OR fcas OR "Etats fragiles" OR "Etat fragile" OR Africa $\mathrm{OR}$ afrique $\mathrm{OR}$ africain $\mathrm{OR}$ Asia $\mathrm{OR}$ asie $\mathrm{OR}$ "Latin America" $\mathrm{OR}$ "Amerique latine" $\mathrm{OR}$ latinoamericain OR "Central America" OR "Amerique centrale" OR "Pacific Island Countries" OR "iles du Pacifique" OR "Eastern Europe" OR "Europe de l'est” OR "Europe oientale” OR Afghanistan OR benin OR "Burkina Faso" OR burundi OR “Central African Republic” OR "Republique centrafricaine” OR chad OR tchad OR Comoros OR comores OR "Democratic Republic of Congo" OR "Democratic Republic of the Congo" OR drc OR "Republique democratique du Congo" OR $r d c$ OR Eritrea OR erythree OR ethiopi* OR gambi* OR guine* OR “Guinea-Bissau” OR “Guinee Bissau” OR “Guinée-Bissau” OR haiti OR "North Korea” OR "Democratic People's Republic of Korea” OR liberia OR madagascar OR malawi OR Mali OR mozambique OR Nepal OR Niger OR rwanda OR senegal OR “Sierra Leone” OR somali* OR "South Sudan” OR soudan OR syri* OR Tajikistan OR tadjikistan OR tanzani* OR togo OR uganda OR ouganda OR Yemen OR zimbabwe OR angola OR Argentina OR Bangladesh OR bhutan OR bhoutan OR bolivi* OR "Cabo Verde" OR “Cap Vert” OR “Cap-Vert” OR cambodia OR cambodge OR cameroon OR cameroun OR "Republic of Congo" OR "Republic of the Congo" OR "Republique du Congo" OR “Cote d'Tvoire” OR "Ivory Coast" OR Djibouti OR Egypt OR "El Salvador” OR Georgia OR georgie OR Ghana OR honduras OR India OR inde OR indien* OR indonesi* OR Kenya OR kiribati OR kosovo OR “Kyrgyz Republic” OR kirghizistan OR laos
Theories of PBF in LMICs 
OR "Lao PDR" OR lesotho OR mauritani* OR micronesi* OR moldov* OR mongoli* OR Morocco OR maroc OR Myanmar OR birmanie OR nicaragua OR nigeria OR Pakistan OR "Papua New Guinea" OR "Papouasie Nouvelle Guinée” OR papouasie-nouvelle-guinée OR philippines OR "São Tomé and Principe" OR "Solomon Islands" OR “iles Salomon" OR "Sri Lanka” OR ceylan OR Sudan OR swaziland OR "Timor-Leste" OR tunisi* OR ukraine OR Uzbekistan OR ouzbekistan OR vanuatu OR vietnam OR "West Bank and Gaza” OR “Cisjordanie et Gaza” OR zambi*))

Keywords used in Base (23 July 2019):

(1) performance-based financing AND theory AND health ("autres formes du mot")

(2) results-based financing AND theory AND health

(3) health theory "financial incentives" "low-income countries"

Keywords used in EBSCO (Business Source Premier + ECONLIT) (24 July 2019):

(1) results based AND financing AND theory AND health (Expanders - Apply related words; Apply equivalent subjects; Search modes - SmartText Searching)

(2) performance based AND financing AND theory AND health (Limiters - Published Date: 19990101-20190631; Expanders - Apply related words; Also search within the full text of the articles; Apply equivalent subjects; Search modes - SmartText Searching)

\begin{abstract}
About the authors
Elisabeth Paul, $\mathrm{PhD}$, is an associate professor at the School of Public Health of the Université libre de Bruxelles and independent consultant. Her key areas of specialization include universal health coverage and health financing policies, performance-based financing, health systems strengthening and aid delivery modalities. Elisabeth Paul is the corresponding author and can be contacted at: Elisabeth. Paul@ulb.ac.be

Oriane Bodson is a PhD student in political and social sciences at the Faculty of Social Sciences of the University of Liège. Her doctoral research focuses on the effects of performance-based financing on health workers' behavior in Benin and Senegal. In recent years, she has participated in several health researches in West Africa (Benin, Burkina Faso, Senegal), mainly on universal health coverage and performance-based financing.

Professor Valéry Ridde, PhD, is a research director at IRD (the French Institute for Research on Sustainable Development), CEPED (IRD-Universités de Paris), ERL INSERM SAGESUD. He is striving to overcome the significant knowledge deficit in implementation science and equity in global health interventions.
\end{abstract}

For instructions on how to order reprints of this article, please visit our website:

www.emeraldgrouppublishing.com/licensing/reprints.htm

Or contact us for further details: permissions@emeraldinsight.com 